9-23-2020

\title{
Population, development, and policy
}

John Bongaarts

Population Council

Michele Gragnolati

S. Amer Ahmed

Jamaica Corker

Follow this and additional works at: https://knowledgecommons.popcouncil.org/departments_sbsr-pgy

Part of the Demography, Population, and Ecology Commons

How does access to this work benefit you? Let us know!

\section{Recommended Citation}

Bongaarts, John, Michele Gragnolati, S. Amer Ahmed, and Jamaica Corker. 2020. "Population, development, and policy." New York: Population Council. 


\section{POPULATION, DEVELOPMENT, AND POLICY}

John Bongaarts, Population Council

Michele Gragnolati, World Bank

S. Amer Ahmed, World Bank

Jamaica Corker, Bill \& Melinda Gates Foundation 


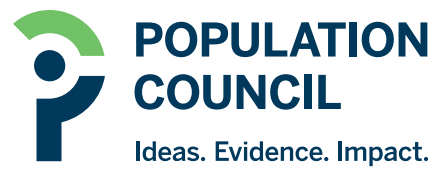

The Population Council confronts critical health and development issues-from stopping the spread of HIV to improving reproductive health and ensuring that young people lead full and productive lives. Through biomedical, social science, and public health research in 50 countries, we work with our partners to deliver solutions that lead to more effective policies, programs, and technologies that improve lives around the world. Established in 1952 and headquartered in New York, the Council is a nongovernmental, nonprofit organization governed by an international board of trustees.

\author{
Population Council \\ 1 Dag Hammarskjold Plaza \\ New York, NY 10017 \\ USA \\ Tel: +1 2123390500 \\ Fax: +1 2127556052 \\ email: pubinfo@popcouncil.org \\ popcouncil.org
}

John Bongaarts is a Distinguished Scholar, Population Council, New York. Email: jbongaarts@popcouncil.org. Michele Gragnolati is Manager for Strategy, Health, Nutrition \& Population, World Bank. S. Amer Ahmed is Economist, Development Prospects Group, World Bank. Jamaica Corker is Program Officer for Data \& Evaluation, Family Planning Program, Bill \& Melinda Gates Foundation.

Suggested citation: Bongaarts, John, Michele Gragnolati, S. Amer Ahmed, and Jamaica Corker. 2020. Population, Development, and Policy. New York: Population Council.

(C) 2020 The Population Council, Inc. 
The extensive literature on population and development yielded few policy-relevant results before the discovery of the demographic dividend. This dividend refers to a rise in per capita income that results from an increase in workers per capita as a population's fertility declines. This paper describes the role of the demographic dividend in economic development in developing countries and summarizes policy options for strengthening the dividend. The first section reviews the demographic transition with an emphasis on its later phases when declining fertility and a changing population age structure produce the dividend. Next, the demographic drivers of the dividend and its potential impact on economic growth are examined. The last sections discuss policy options. Special attention is given to the role of voluntary family planning programs to meet rising demand for contraception thus accelerating the fertility decline and increasing the dividend when demand for smaller families is growing. The focus throughout is on sub-Saharan Africa (SSA), the region that has experienced little demographic dividend but where the potential for a future dividend is greatest. 
The extensive literature on population and development has identified several possible ways in which demographic trends can affect human welfare either positively or negatively. Since the middle of the twentieth century, understanding of the impact of demographic change on the economy has expanded rapidly, with different schools of thought gaining and losing dominance in successive periods accompanied by vigorous debate.

In the 1950s, the UN's population projections predicted the large expansion in human numbers that subsequently occurred in the second half of the twentieth century (United Nations 1954,1958$)$. When these projections were first published, they led to widespread concern about the potential adverse consequences of rapid population growth for human welfare and the environment, especially in the poor countries of Africa, Asia, and Latin America. Malthusian concerns that ever-growing numbers of humans pose a threat to longterm human survival by exhausting limited natural resources resurfaced (Ehrlich 1968; Meadows et al. 1972). In addition, economists discovered economic reasons for concern about adverse development effects of rapid population growth. Coale and Hoover (1958) argued that the savings needed to maintain or raise human and physical capital per capita in a society are higher in rapidly than in slowly growing populations. Population growth thus absorbs savings that could be used to increase capital intensity and raise per capita output. Coale and Hoover also concluded that rapid population growth leads to a high proportion of nonproductive children in the population, which limits savings needed for growing economies. From the 1950s to the mid-1970s, concerns about the adverse economic and environmental effects of rapid population growth dominated academic, political, and popular thinking (NAS 1971). In an effort to slow rapid population growth, governments, particularly the United States through USAID, and foundations made large investments in family planning programs in the developing world during this time (Donaldson 1990; Donaldson and Tsui 1990; Harkavey 1995; Sinding 2007; May 2012).

However, detailed empirical studies from the late 1960s to the 1980s failed to confirm a substantial adverse effect of demographic change on development (Kelley 2001; Headey and Hodge 2009). For example, the correlation between the population growth rate and the growth rate of per capita output of countries turned out not to be significantly negative. This finding contradicted expectations (Kuznets 1967; Kelley 2001) and led to a revisionist view that population is largely a neutral factor in development (Simon 1981). A review of the evidence by the National Academy of Sciences (NAS) in 1986 was highly guarded and qualified about the effects of population growth (NAS 1986).

This revisionist view was overturned during the 1990s as more sophisticated models and longer time series of data became available. New studies again found an important role for demographic variables (Kelley 2001; Headey and Hodge 2009). Seminal research by Barro $(1991,1997)$ identified fertility decline as an important factor in economic growth. In addition, the previously insignificant correlation between population growth and growth of per capita output turned in the expected negative direction with data from the 1980s and 1990s (Kelley and Schmidt 1995, 2001; Headey and Hodge 2009). A plausible explanation for these initially puzzling findings was provided in a thorough review of different modeling approaches by Kelley and Schmidt $(1995,2001)$. They discovered shortcomings in a number of past analyses and, after correcting these, they concluded that declines in mortality, fertility, and population growth all have positive effects on economic growth per capita. These findings helped explain 
the change in significance over time in the link between population and economic growth. For example, the studies using pre-1980 data often included many developing countries that were experiencing rapid mortality decline as well as accelerating population growth. According to Kelley and Schmidt, the former's positive effect on economic growth was offset by the latter's negative effect, thus producing an absence of a correlation. In subsequent decades, mortality decline slowed, fertility declined rapidly, and population growth slowed. The negative correlation between growth and development observed from the 1980s onward was attributable to declines in fertility and declining growth rates.

In the 1990s, the finding that fertility decline had a positive impact on development was of great interest to policymakers and led to a set of new studies by economists of what is now called the "demographic dividend" (see Section II for further discussion). With the right policies, this demographic dividend offers a potential boost to GDP per capita when fertility decline leads to a reduction in the proportion of children in a population, and hence to a rise in the ratio of workers to dependents. The period during which the dividend is available is bounded but can range up to decades.

Our overall objective here is to document the role of the demographic dividend in economic development in developing countries and to summarize policy options for strengthening the dividend. The paper is organized into four sections. First, we describe the demographic transition and the evolution of key demographic variables over the period from 1950 to 2100 , with an emphasis on declining fertility and the changing population age structure that are the drivers of the dividend. Next, we examine the demographic drivers of the dividend and its potential impact on economic growth and poverty. Third, we outline theories of fertility decline and the desire for smaller families. The fourth section discusses policy options for enhancing the dividend by expanding access to voluntary family planning programs to meet rising demand for contraception. The focus throughout our analysis is on sub-Saharan Africa (SSA), the only global region that has not yet largely experienced the demographic dividend and thus where the potential for a future dividend is greatest.

\section{Demographic transition}

The "demographic transition" refers to a process of long-range demographic change observed historically in populations around the world. During the transition, demographic conditions evolve from high mortality and high fertility to low mortality and low fertility, with a period of rapid population growth in the middle of the transition (Chesnais 1990, 1993; Kirk 1996). The demographic transition model describes the distinct patterns of secular changes in birth, death, and growth rates that have historically accompanied the transformation of traditional agricultural societies into modern industrial ones. The body of research developed to explain these trends is referred to as demographic transition theory.

\section{The transition model}

A complete transition is typically divided into five successive stages (Chesnais 1990). Stage 1: pre-transition (high birth and death rates, and little or no population growth, typical of traditional agricultural societies); stage 2: accelerating population growth (declining death 
FIGURE 1: THE FIVE STAGES OF THE DEMOGRAPHIC TRANSITION

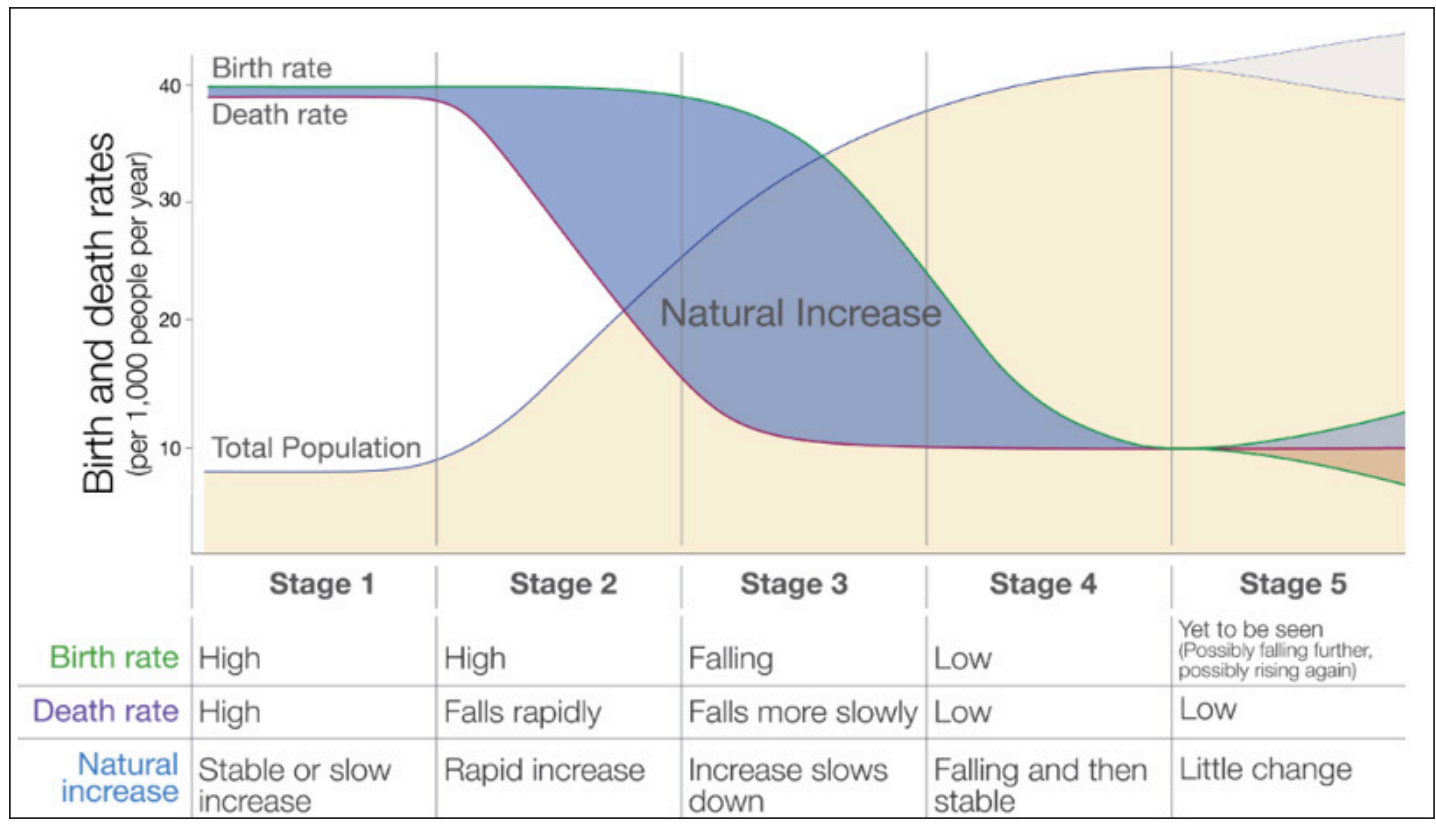

Source: OurWorldinData.org, licensed under CC-BY-SA by Max Rosen.

rate while birth rate remains high); stage 3: continued population growth (birth rate decline offsets death rate decline), stage 4: decelerating growth (rapid birth rate decline narrows the gap between birth and death rates); and stage 5: post-transition (birth and death rates low and growth near zero, typical of modern societies) (Figure 1). The key events driving the demographic transition are the onset of the mortality transition in stage 2 and the onset of the fertility transition in stage 3.

A full transition can last more than a century, during which the size of the population typically grows by an order of magnitude. For example, the world population, estimated at about 1 billion in 1800, now stands at 7.6 billion and is projected to reach 11 billion in 2100 (United Nations Population Division 1999, 2019). This growth during the demographic transition results in a transition multiplier of 11 between 1800 and 2100 . The transition in today's developed countries started earlier and has proceeded at a slower pace than for contemporary developing countries. As a result, the transition multipliers for the period 1800-2100 for developed and developing countries differ substantially at 6 and 13, respectively (United Nations Population Division 1999, 2019).

While past transitions have generally followed the outlines of the model, countries vary widely in the timing of their mortality and fertility transitions as well as the durations of the various stages. In addition, fluctuations in birth and death rates often occur.

\section{Transition theory}

The earliest elements of a transition theory were proposed by Thompson (1929) and Landry (1934) and were later refined by Davis (1945), Notestein (1945), and others (e.g., Chesnais 
1993; Caldwell 2007). The theory has two parts, dealing respectively with the causes of the mortality and the fertility transitions.

There is broad agreement about the drivers of past mortality declines in the developed world (Chesnais 1990, 1993; Livi-Bacci 1992; Riley 2001; Cutler, Deaton, and Lleras-Muney 2006). The mortality transition started in England and Northern Europe early in the nineteenth century and spread subsequently to other industrializing countries in Europe and elsewhere. Life expectancy at birth rose from less than 40 years in the eighteenth century to around 50 years by 1900 (Livi-Bacci 1992; Human Mortality Data base 2019). Several factors contributed to this improvement in longevity: public health measures reduced exposure to water- and food-borne diseases, better nutrition improved resistance to disease, and inoculation and vaccination prevented certain infectious diseases. The largest impact of these factors on life expectancy and overall mortality rates came from declines in death rates among infants and children, where mortality had been concentrated in pre-transition societies.

Mortality decline accelerated after 1900 , driven primarily by a) the institutional acceptance of the germ theory of disease that led to a range of measures to reduce exposure and transmission, and b) the development of antibiotics that brought most infectious diseases under control. By the 1950s, life expectancy at birth in the most advanced countries had risen to 70 years and all but a small percent of infants survived the first years of life. These countries have now reached the final stage of the mortality transition, in which mortality is concentrated in older ages and health care focuses substantially on the treatment and prevention of chronic diseases among the older adult population, e.g., heart disease, cancer, and diabetes. While further progress is being made in the treatment of these diseases, it is likely that future improvements in life expectancy will be less rapid than over the past century, given the substantial gains in infant and child survival in nearly all countries.

The mortality transition in the regions that developed later or are still developing followed a quite different pattern, with later but accelerated declines in mortality compared to the European and North American experiences. Declines in mortality in these developing regions were modest through the early part of the twentieth century: by the early 1950s life expectancy was only 38 years in Africa and 42 years in Asia, with Latin America faring somewhat better with a life expectancy of 51 years (United Nations Population Division 2019). However, over the past half century mortality conditions in large parts of the developing world have improved more rapidly relative to historical patterns in the developed world due to rising incomes, improved nutrition levels, access to medical care, and especially the implementation of public health measures and the availability of antibiotics and other drugs. Today, life expectancy at birth in Latin America and the Caribbean (75) and Asia (73) is similar to that of Europe in the 1960s. Africa, the least developed continent, has a life expectancy of 63 years and lags other global regions even though life expectancy has risen by about 10 years over the past half century (United Nations Population Division 2019).

The fertility transition in the industrialized countries started in the late 1800 s. Aside from a substantial interruption of this trend during the post-war baby boom, these countries now have very low fertility. In fact, in several countries (e.g., Japan and Russia) the birth rate has fallen and stayed below the death rate, leading to sustained population decline (United Nations Population Division 2019) and concerns about the economic impact of aging and 
FIGURE 2: POPULATION SIZE

RATIO (2015=1)

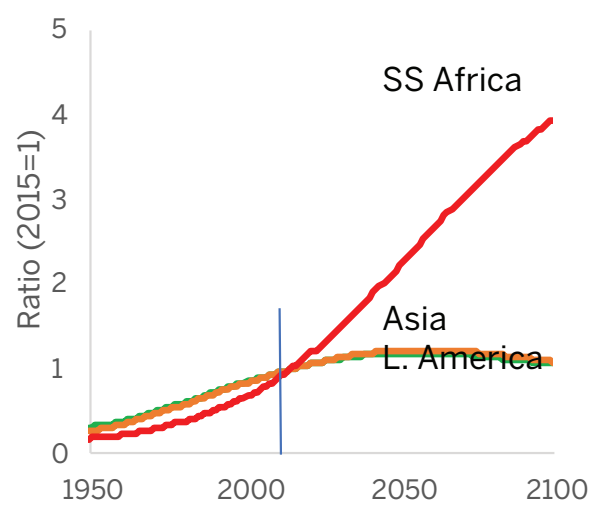

FIGURE 3: FERTILITY TRENDS

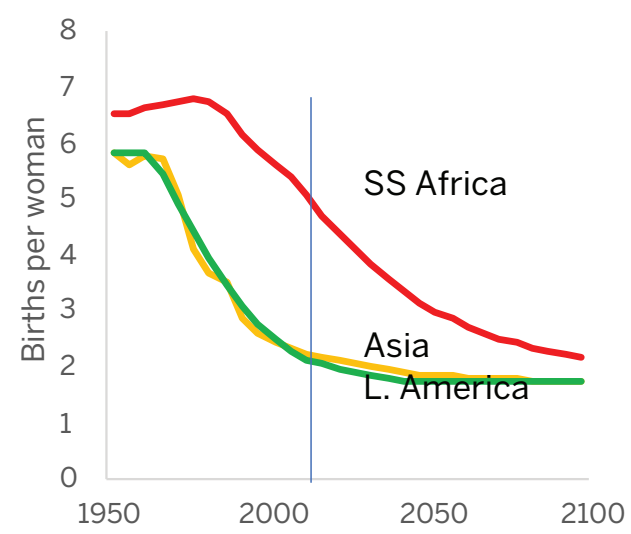

Source: United Nations Population Division 2019.

shrinking populations. Declines in fertility in developing regions did not begin until the $1960 \mathrm{~s}$ and 1970s, and were largely confined to Asia, Latin America, and North Africa. In contrast, in SSA fertility remains relatively high although by now most African countries have experienced at least some decline. A fuller discussion of the debate about the causes of fertility changes will be provided in Section III of this paper.

Demographic transition theory has been criticized for being too general and for having little predictive power (Hauser and Duncan 1959; Kirk 1996). Its main weakness is that the conditions for the timing of onset of the mortality and fertility transitions are highly variable and are not closely tied to any development indicators. Nevertheless, the theory is widely cited and used, and it is correct in predicting general declines in death and birth rates as societies develop (Coale 1973).

\section{Key transition trends}

Today most of the world is at or near the end of the demographic transition. Europe, North America, and East Asia have reached transition stage five, with near-zero or even negative population growth. Latin American and South Asian countries are mostly in stage four, with declining fertility and growth rates. However, SSA is still in mid-transition, with substantial declines in mortality but relatively high birth rates and rapid growth. These different transition stages at which regions find themselves today imply large regional differences in future population growth. According to UN projections, the population of SSA is expected to quadruple between 2015 and 2100 (from 1 to 4 billion), while the populations of Asia and Latin America, which are also growing, are forecast to be only slightly larger in 2100 than they are today (see Figure 2).

The main causes of these divergent regional projected population growth trajectories are differences in levels and trends in fertility. Figure 3 plots estimates and projections of fertility (measured in births per woman) over the 1950-2100 period. In the 1950s and 1960s, women in Asia, Latin America, and SSA had on average about six children. These levels are 
FIGURE 4: PERCENT OF

POPULATION UNDER AGE 18

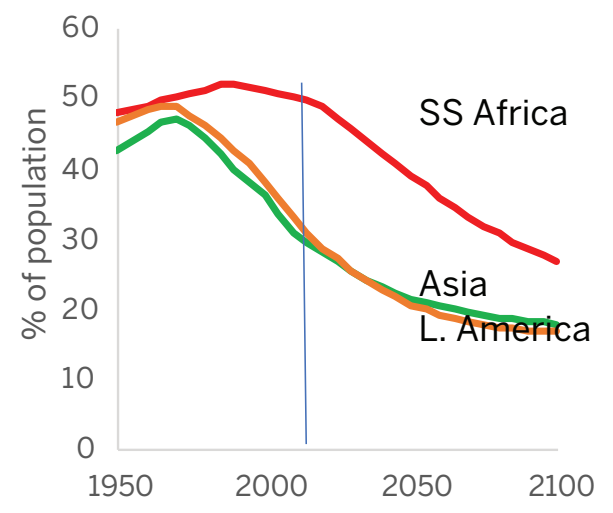

FIGURE 5: PERCENT OF POPULATION AGED 18-64

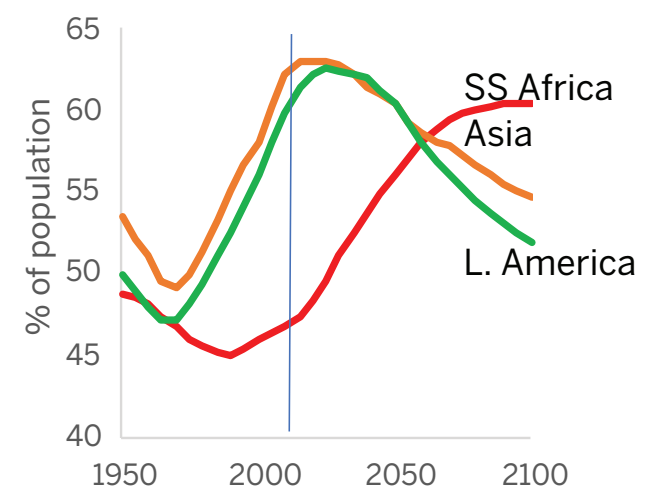

Source: United Nations Population Division 2019.

approximately the same as have prevailed for much of history and reflect a near absence of contraception.

In Asia and Latin America, steep fertility declines began around 1970 with the rapid uptake of contraception. These two regions are today close to the "replacement" level of two surviving children per woman that eventually leads to population stabilization, where a population has a growth rate of zero. In contrast, fertility across most of SSA remained high until the end of the twentieth century. Projections of future fertility decline in the region vary but nearly all forecasts predict it will decline slowly in the coming decades relative to declines in Asia and Latin America. Elevated fertility, coupled with further declines in mortality, will lead to continuous population growth in SSA throughout the remainder of this century.

Fertility is the most central component of population dynamics. In addition to determining population size and growth trajectories, fertility changes have an important direct effect in shaping the age distribution. For example, about half of the population was under age 18 before 1970 in Asia, Latin America, and SSA (see Figure 4). However, as fertility declines proceeded in Latin America and Asia in the 1970s and 1980s, the proportion of children declined rapidly to around 30 percent by 2015 (United Nations Population Division 2019). In contrast, the slower fertility decline in SSA resulted in a much slower decline in the proportion of the population under 18. As expected, comparison of Figures 3 and 4 shows a close correspondence between trends in fertility and trends in the child proportion, although the latter follows the former with a delay of one to two decades.

Another indicator of the changing age structure is the proportion of the population of working age (usually taken to be between 18 and 64 years). Figure 5 plots estimates and projections of regional averages of this proportion from 1950 to 2100 . The substantial swings up and down over time are, not surprisingly, inversely related to changes in the proportion of the population under age 18. In Asia and Latin America, the substantial declines in the proportion under age 18 after 1970 led to a sharp rise in the proportion aged 18-64 between 1970 and about 
2015. A quite different pattern is evident in SSA, however, where the later and slower onset of the fertility decline leads to a later and slower onset of decline in the child proportion of the population and hence to a delayed rise in the proportion of working age relative to other regions.

A demographic dividend occurs during the years when the proportion of the working age population rises relative to dependents (children and the elderly). This dividend is highest when fertility declines are rapid, leading to substantial increases in the proportion of the population that is "economically active" in a relatively short period of time. This window of opportunity for accelerated economic growth from changing population age structures provided by the demographic dividend is today essentially completed in Asia and Latin America, but in SSA the timing and the size of a demographic dividend are still uncertain and will depend largely on future trends in fertility.

As will be discussed in the next section, these changes in the population age distribution, as well as the speed and size of these changes, can have important implications for economic growth and poverty reduction.

\section{The demographic dividend, economic growth, and poverty ${ }^{1}$}

\section{The demographic dividend}

The substantial age-structure shifts that are caused by fertility decline in the later stages of demographic transitions can boost economic growth through the demographic dividend (Kelley and Schmidt 1995, 2005, 2007; Higgins and Williamson 1997; Bloom and Williamson 1998; Bloom and Canning 2004; Lee and Mason 2006; Mason and Kinugasa 2008; Bloom et al. 2009; Eastwood and Lipton 2011; Canning, Raja and Yazbeck 2015; World Bank 2015a; Ahmed et al. 2016; Cruz and Ahmed 2016; Kara, Canning, and Wilde 2017). The economic literature on the topic makes a distinction between two types of demographic dividend.

The first demographic dividend (also called the arithmetic dividend or the labor-force accelerating effect) refers to the rise in per capita income that results, other things being equal, from an increase in workers per capita as the population age-structure changes. This first dividend can be considered mechanical and is essentially guaranteed as the age structure changes with decreases in fertility. This effect is independent of any changes or improvements in output per worker, savings and investments, and the employment rate. Estimates suggest that for some countries the first demographic dividend explains between 9.2 to 15.5 percent of per capita economic growth over the 1960-2000 period (Mason and Kinugasa 2008). Though the first demographic dividend can persist for decades, it is ultimately transitory and is eventually followed by economic pressures related to population aging.

The second demographic dividend refers to additional increases in per capita income that result from changes in economic behavior as the age structure changes. In particular, national savings and investment rates often rise as income-earners become a greater share of the population. Individuals are typically net savers when they are of working age, but they tend to be predominantly consumers when they are children and elderly. As fertility declines, there are fewer children to support and national savings tend to rise (e.g., Higgins and Williamson 
1997; Kelley and Schmidt 2005; and Kinugasa and Mason 2007). For example, an increase of 1 percentage point in the share of the working-age population is associated with an increase of 0.6 to 0.8 percentage points in savings (World Bank 2015a; Cruz and Ahmed 2016). Greater investments in fewer children, resulting in a more skilled workforce, can in turn lead to faster productivity growth, provided this workforce is productively employed. In addition, labor supply may expand as mothers with lighter childrearing responsibilities find it easier to enter (and remain in and/or re-enter) the labor market.

The causality underpinning the association between working-age population shifts and economic growth thus occurs through multiple pathways: through an increase in the supply of workers relative to the total population, through a rise in savings leading to a higher capital per worker ratio, and through more investment in human capital. While these channels can work simultaneously, the first and second dividends differ not only in their transmission mechanisms but also in the time horizon over which they are at work: the first dividend on average occurs earlier than the second dividend, but the two typically overlap. As a result of these two demographic dividends, an increase of 1 percentage point in the working-age population share is estimated on average to boost GDP per capita growth rates by 1.1 to 2.0 percentage points (World Bank 2015a; Cruz and Ahmed 2016).

\section{Modeling the demographic dividend}

The magnitude of the future potential demographic dividend in SSA depends on trends in a range of country-level economic and demographic variables that are influenced by the global economy. For present purposes we rely on the World Bank LINKAGE model (a global general equilibrium model), and the newly developed Global Income Distribution Dynamics (GIDD) tool. LINKAGE provides the economy-wide effects of demographic change over time and the GIDD microsimulation framework generates income distributions under various scenarios (Bussolo, de Hoyos, and Medvedev 2010; Bourguinon and Bussolo 2013). GIDD draws on household-level survey data benchmarked to 2010 to estimate income distributions that account for demographics, household characteristics (e.g., age, gender, and education of different members), sector of employment, skill premia on wages, and income.

In assessing the economic impact of alternative demographic trends, our analysis relies on four demographic scenarios (constant fertility, high fertility, medium fertility, and low fertility) and the associated projections of population age structures published by the United Nations Population Division (2015). The medium variant represents the most likely trajectory while the high variant assumes fertility to be a half birth above the medium variant and the low variant assumes future fertility to be a half birth below the medium variant. The economic results associated with these four scenarios are obtained by stimulating economic growth projections using the structural reforms scenario with acceleration in Total Factor Productivity from Bou Habib and Lofgren (World Bank 2017).

An analysis with the LINKAGE model by Ahmed et al. (2016) concluded that accelerated demographic change could result in 11 to 15 percent of GDP volume growth and approximately 40 to 60 million fewer poor by 2030 for SSA. ${ }^{2}$ It should be noted that the scenario analysis does not account for discrete structural changes in the economy such as may occur as a result of unanticipated infrastructure investments. As such, the simulation results should be considered illustrative and highlighting the marginal economic impacts of demographic change. 


\section{FIGURE 6: FERTILITY SCENARIOS AND PROJECTED PROPORTION OF THE POPULATION UNDER-15 FOR THE DRC}

a. Total fertility rate by fertility scenario (births per woman)

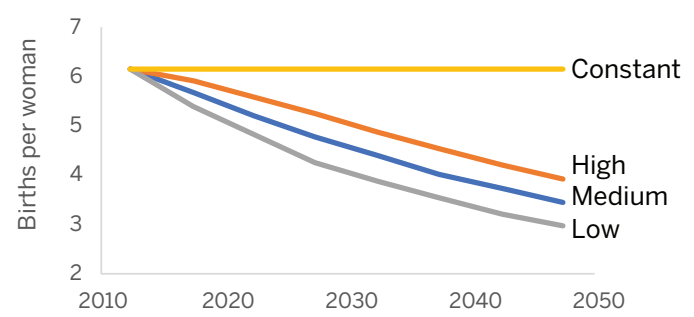

b. Share of children in population by fertility scenario (percent)

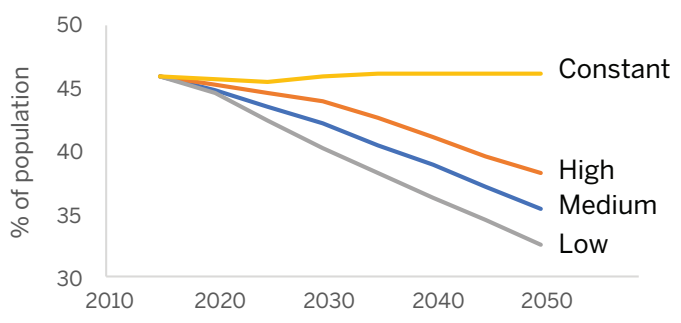

Source: Data from United Nations Population Division (2015).

\section{Fertility decline and the demographic dividend in Democratic Republic of Congo}

We use the Democratic Republic of Congo (DRC) as an example of a country in which modest accelerations in fertility decline can lead to substantial changes in its projected age structure. The DRC had a total fertility rate (TFR) of 6.15 in 2015, one birth per woman above the average for the continent. However, over a quarter of married women (27.7\%) have an unmet need for family planning, implying that women have on average more children than they would like.

Under the UN's median fertility scenario, the TFR is projected to fall to 4.77 by 2030 and 3.43 by 2050 (Figure 6a). The UN does not specify how these changes will be brought about, but, as will be shown below, it will likely involve a combination of socioeconomic change and meeting the current unmet need for family planning.

With this fertility decline in the medium scenario, the population share of children under 15 will decline steadily for several decades to come (Figure 6b). In 2015, children under 15 accounted for 46 percent of the population. This proportion is expected to decline slowly under this scenario to approximately 42 percent in 2030 and 35 percent in 2050.

The working-age population in the DRC in 2015 accounted for 51 percent of the population and is projected to account for more than 60 percent of the population by 2050 under the UN's medium fertility scenario (Figure 7). If, however, fertility declines are slower, as under the high-fertility scenario (which assumes some fertility decline from current levels, albeit more modest), then the 2050 population share of working age will be lower, at 58 percent. In contrast, if fertility reductions are faster in the future, as under the UN's low fertility scenario, potential workers will account for 63 percent of the population by 2050 .

To illustrate the potential impact of fertility changes on economic growth, we estimate the economic implications of alternative demographic scenarios, accounting for both age distribution and population size, with simulations of DRC's economic growth trajectory to 2050 using the LINKAGE model (Figure 8). Using a constant set of assumptions of economic growth and the UN's medium fertility scenario, real GDP per capita in the DRC is projected to grow from $\$ 452$ (constant US\$) in 2015 to $\$ 4,311$ by 2050 . With the same set of assumptions 
FIGURE 7: SHARE OF WORKING AGE PEOPLE IN TOTAL POPULATION BY FERTILITY SCENARIO (PERCENT), DRC

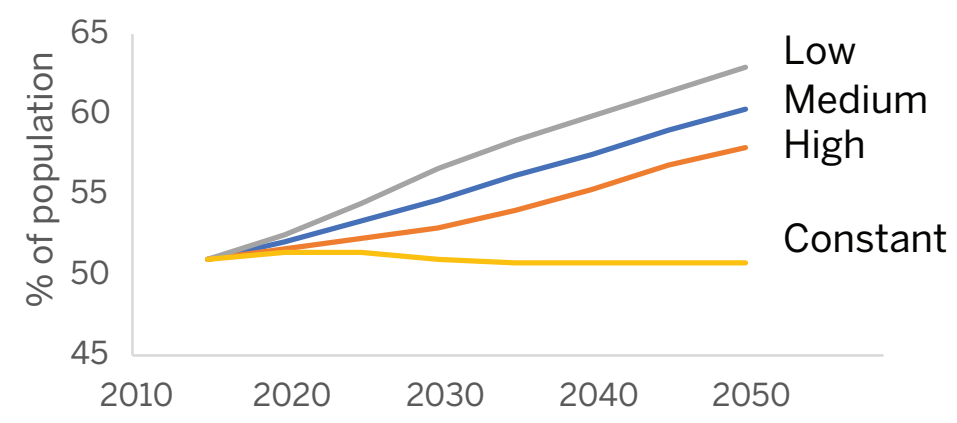

Source: Data from United Nations Population Division (2015).

FIGURE 8: REAL GDP PER CAPITA GROWTH IN 2050 BY FERTILITY SCENARIO, DRC

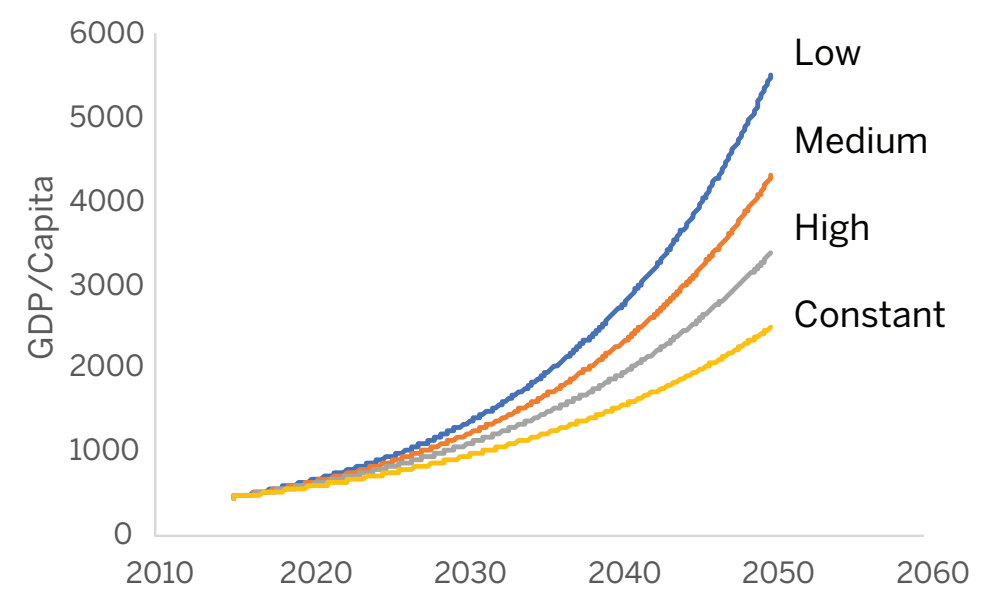

Source: Simulation results from LINKAGE.

of economic growth under the high-fertility scenario, however, growth is projected to be more modest, reaching only $\$ 3,391$ by 2050 . Under the low-fertility scenario, per capita income in 2050 is projected to be much higher at $\$ 5,527$. A comparison of these high- and low-fertility scenario projections indicates that, other things being equal, a one-child difference in DRC's fertility rates by 2050 would result in age-structure changes that could lead to a 63 percent difference in real GDP per capita in one of the world's poorest countries.

Figure 9 illustrates the projected growth rates of real GDP per capita for the DRC from 2018 to 2050 , decomposed into two components: 1 ) productivity growth and other impacts, and 2) acceleration attributable to demographic changes (i.e., age-structure changes favorable to a demographic dividend). These results imply that age-structure changes resulting from declining fertility alone could increase the income per capita growth rate by $0.44,1.05$, and 1.76 percent per year in 2018-50 for the high-, medium-, and low-fertility scenarios, respectively. 
FIGURE 9: DECOMPOSITION OF AVERAGE ANNUAL REAL GDP PER CAPITA GROWTH RATES, BY FERTILITY SCENARIOS WITH STRUCTURAL REFORMS (DECOMPOSED BY CONTRIBUTING FACTOR, 2018-50, IN PERCENT), DRC

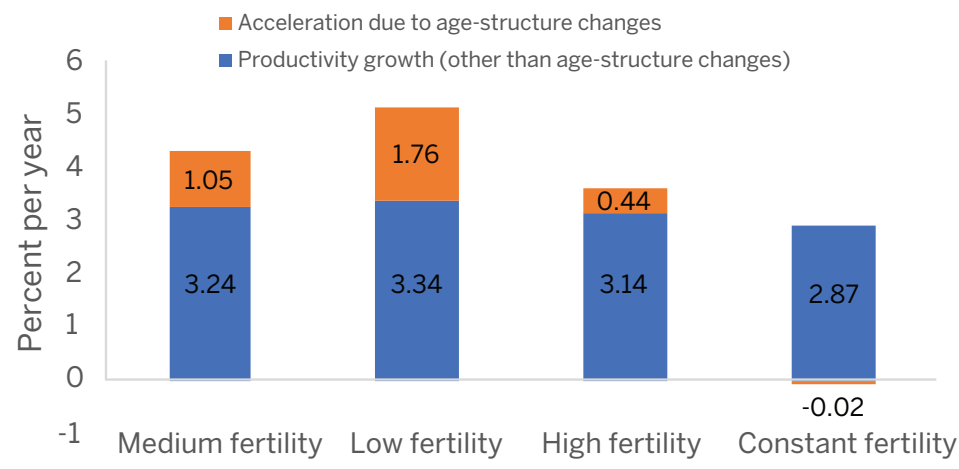

Source: Simulation results from LINKAGE.

FIGURE 10: CONTRIBUTIONS TO AGE-STRUCTURE-RELATED INCOME PER CAPITA ACCELERATION, BY FERTILITY SCENARIOS WITH STRUCTURAL REFORMS (2018-50, IN PERCENT)

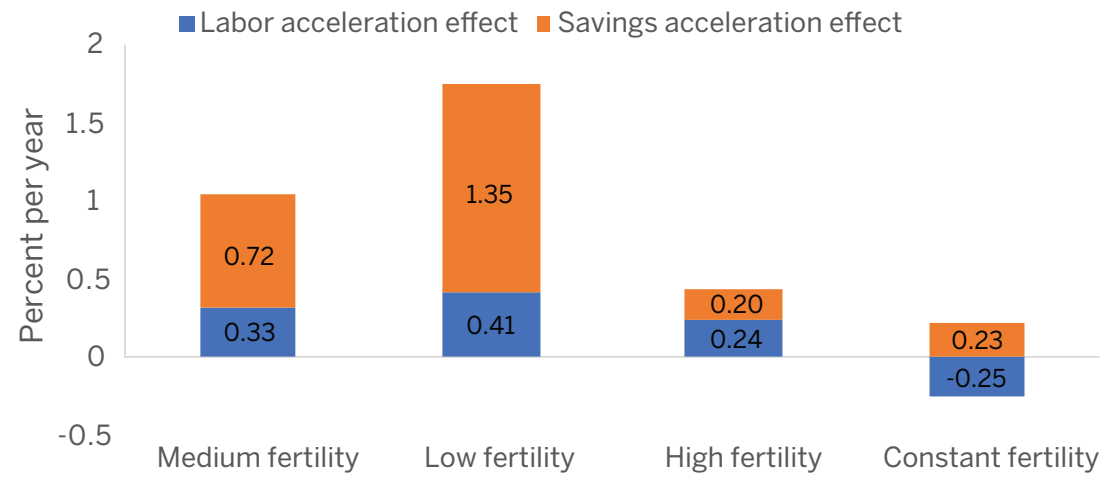

Source: Simulation results from LINKAGE.

Figure 10 plots the age-structure effects on the per capita growth rate, decomposing it into the first and second dividends. These results indicate that the main demographic contributions to growth in per capita income under these scenarios are from the savings acceleration effect (leading to faster capital accumulation), rather than the acceleration of the labor force.

Though these scenario projections are illustrative, they nonetheless demonstrate the substantial impact declines in fertility can have on economic growth, particularly if the right structural reforms are implemented during the demographic dividend window. Expanding family planning programs to meet the contraceptive needs of the Congolese population, now and in the future, will have the positive by-product of producing an age structure that will 
contribute to accelerated economic growth. A key question for policymakers therefore is how fertility decline can be accelerated, by strictly voluntary means, in populations where actual fertility exceeds desired fertility. This is the subject of the remaining sections.

\section{Theories of fertility decline}

The causes of past declines in fertility are the subject of continuing debate. Over time, several theories and their variants have been developed, each with important new insights that are crucial to an understanding of reproductive change and to the design of optimal policies.

\section{Conventional theories}

Original demographic transition theory proposed various possible causes of the fertility decline that occurred in the West from the late nineteenth century through the 1930s (Davis 1945; Notestein 1945). In traditional rural agricultural societies, fertility was assumed to be necessarily high to offset high mortality and to ensure population survival. This high fertility was achieved by a near universal absence of conscious contraceptive practices. As a society modernized, economic and social changes such as industrialization, urbanization, education, and declining mortality led to the onset of the fertility transition. The rising costs of children (e.g., for schooling) and their declining economic value (e.g., for labor and old-age security) were the central forces believed to be driving the decline in desired family size. This in turn increased the demand for and adoption of birth control to implement changing reproductive preferences.

This conventional framework, still regarded as broadly valid, has been the basis for various elaborations by economists, sociologists, and demographers. Contributions by economists to fertility theories focused on the micro-economics of reproductive decision-making (Becker 1960, 1965, 1981; Willis 1974; Schultz 1976, 2002; Lee and Bulatao 1983). Parents are assumed to be rational actors who aim to maximize the utility derived from various choices they make given time and resource constraints. This decision-making includes choices related to conventional goods and services as well as to children. In choosing a family size, parents have preferences not only for the number of children but also for their "quality" (i.e., their education and economic opportunities). As countries develop, parents increasingly want higher-quality children which raises their cost, thus leading parents to want smaller families. This school of thought is usually referred to as "demand theory."

Empirical evidence is broadly consistent with demand theories: countries' fertility levels are inversely related to socioeconomic indicators such as GDP per capita, life expectancy, child survival, education, and urbanization (Bryant 2007). As countries develop, fertility behavior broadly changes along the lines proposed by demand theories. This is the course taken by the now-developed world, where fertility declines began in the late-nineteenth century, and also by many developing countries in recent decades. However, there are notable exceptions to this generalization. For example, fertility has declined rapidly in a few countries during periods with unfavorable development conditions (e.g., in Bangladesh, Indonesia, Nepal, and Sri Lanka in the 1970s and 1980s). The general explanations for these unexpected fertility declines are the priority given by governments to social development (e.g., schooling and women's empowerment) and the widespread implementation of family planning and health programs. 
While social development certainly played a crucial role, it is critical to note that to date, no fertility decline has been observed in a poor and largely illiterate country in the absence of a strong family planning program (see Section IV).

A weakness of conventional demographic transition theory is its generality. Many socioeconomic indicators are correlated with fertility in bivariate cross-sectional comparisons of countries, but for many decades there was no agreement on the dominant driver of fertility decline. However, the extensive literature on this topic increasingly emphasized the central role of education and especially women's education (Cochrane 1979; Summers 1992a, 1992b; Schultz 1994; Jejeeboy 1995; Hadden and London 1996; Kravdal 2002; Lloyd 2003; Gaylor 2005; Cleland 2009; Murtin 2013; Lutz and Skirbekk 2014). A recent comprehensive regression analysis of the determinants of fertility using time series of data from 1870 to 2000 concludes that "....average years of primary schooling among the adult population, rather than income standards, child mortality, or total mortality rates, drive fertility down by about 40 percent to 80 percent when those years grow from zero (no illiteracy) to six years (full literacy). This result is robust to a variety of specifications, samples, and econometric models" (Murtin 2013, p. 617). Similarly, Cleland (2009, p. 183) concludes: "Education of adults persistently emerges as the single most powerful predictor of their demographic behavior." Lutz and Skirbekk (2014, p. 15) agree: “...educational attainment is not just one of many socio-economic factors that matter...[it] is the single most important source of empirically observable population heterogeneity."

Several causal forces have been proposed for the effect of women's education on fertility, including: greater autonomy in decision-making, more knowledge about reproduction and contraception, higher potential for earnings, and rising opportunity costs of childbearing (Jejeebhoy 1995; Diamond, Newby, and Varle 1999; Lloyd 2003). A related set of studies examines the role of mass schooling which may lower fertility in developing countries by reducing the child's potential to work in or outside the home, raising the costs of children, speeding up cultural change, and propagating middle-class values (Caldwell 1980).

While there is a growing consensus about the key role of education as a driver of fertility decline, as well as about the minor roles of GDP per capita and percent urban, there is less agreement about the effect of child mortality, specifically in contemporary contexts. Several authors argue for a role of mortality decline as a determinant of fertility (Cleland 2001b; Angeles 2010; Canning, Raja, and Yazbeck 2015) but others have argued that research has not produced concrete findings in part because of methodological shortcomings (Wolpin 1998), leaving a consensus on the mechanisms and impact of mortality decline on fertility decline unresolved (Angeles 2010; Murtin 2013). It is possible that Notestein's original views, that mortality decline is a necessary but not sufficient condition for fertility decline and that social and economic changes are needed to bring about reproductive change, are correct (Notestein 1945). The "necessary but not sufficient" hypothesis is consistent with the pattern observed in a number of contemporary Western African countries (e.g. Chad, DRC, Mali, and Niger), where child mortality has been reduced by half since the 1950s, but these improvements have only been followed by minor fertility declines (United Nations Population Division 2019). 


\section{Revisionist theories}

Since the 1970s the fertility component of conventional demographic transition theory has been found incomplete in several respects and questions have been raised about demand theories of fertility. First, a crucial assumption of early demand theories is that the cost of contraception is sufficiently low to be ignored. This assumption became questionable in the late 1960s and early 1970s when new evidence documented the frequent use of induced abortion in both developed and developing countries and demonstrated that unintended pregnancies were common (Rochat et al. 1980; Tietze 1981). These findings contributed to an influential revision of the earlier economic theories of fertility by Richard Easterlin (Easterlin 1975, 1978; Easterlin and Crimmins 1985). His framework for the determinants of fertility recognized that the cost of birth control (broadly defined to include economic, health, psychological, and social obstacles) could be substantial, thus leading to significant numbers of unplanned pregnancies. In addition, the framework acknowledged the role of biology in childbearing outcomes, specifically that without efforts to control conception, women who are sexually active will bear large numbers of children because the reproductive years last decades. Thus, to avoid having "excess" children, parents must practice birth control, a fact that makes the "acquisition" of children fundamentally different from the purchase of durable goods.

A second fundamental challenge to demand theories came in the 1980s when empirical tests of conventional theories were conducted using historical and contemporary data and failed to find the tight link between development indicators and fertility expected from conventional theories. For example, the massive study of province-level data from European countries for the period 1870-1960 (Knodel and van de Walle 1979; Coale and Watkins 1986; Watkins 1986, 1987) yielded two surprising conclusions: (1) socioeconomic conditions were only weakly predictive of fertility declines, and transitions started at widely varying levels of development; and (2) once a region in a country had begun a decline, neighboring regions sharing the same language or culture followed after short delays, even when they were less developed. Likewise, results from numerous fertility surveys of women in 41 developing countries in the 1970s and early 1980s failed to find the expected dominant influence of economic characteristics on fertility (Cleland 1985; Cleland and Wilson 1987). Moreover, levels and trends in fertility in the developing world since the 1950 s deviated widely from expectations (Bongaarts and Watkins 1996). For example, Hong Kong and Singapore started their fertility transitions when they had much higher levels of income, literacy, and urbanization than Bangladesh, where fertility decline began when the country was still largely rural and agricultural. Thus, although most traditional societies do have high fertility when compared to modern industrial societies, the transition itself is poorly predicted by customary quantitative measures of development.

These unexpected findings required a revision of thinking about the fertility transition and led to the development of theories of the "diffusion" of innovations (e.g., Rogers 1973, 2003; Knodel and van de Walle 1979; Retherford and Palmore 1983; Cleland and Wilson 1987; Watkins 1987; Montgomery and Casterline 1993, 1996; Bongaarts and Watkins 1996; Casterline 2001; Hornik and McAnany 2001; Kohler 2001; Cleland 2001a). Diffusion refers to the process by which new technologies, ideas, behaviors, and attitudes spread within a population through a variety of mechanisms (e.g., social networks, opinion leaders, media). This spread is most rapid within linguistically and culturally homogeneous populations and 
is often largely independent of social and economic changes. In particular, the diffusion of information about methods of contraception is now considered an important mechanism of fertility change. New ideas about the costs and benefits of children that may lead to a smaller desired family size are also subject to diffusion processes.

A third issue left relatively unexplored by earlier demand theories of fertility is the key role of social norms. Traditional demand theory focused on the reproductive behavior and decisionmaking of individuals or couples, but largely ignores how this behavior is affected by social norms about how people ought to behave. This is an important obstacle to the introduction of new behaviors such as contraceptive use in societies where it has been absent. The existence of social norms also explains why the fertility of women in a given socioeconomic class (e.g., education) varies so much between countries. This finding can be explained in part by the fact that the fertility of a woman depends not only on her own education but also on that of her community (Kravdal 2002): as the level of education within a community increases over time, norms concerning desired family size within that community decline, thus contributing to reduced fertility of all women in the community.

Traditional norms, including those that encourage high fertility, tend to become less influential as societies develop and education levels rise. While conventional demographic and economic theories emphasize the demand-driven nature of reproductive change and leave little or no role for family planning programs (Pritchett 1994), the now widely accepted revisionist theories assign crucial roles to the cost of birth control and to diffusion mechanisms. These findings provide a strong rationale for family planning programs that can accelerate fertility transitions by providing information that can alter parents' evaluation of the costs and benefits of children and, more directly, reducing the various costs of contraception to those who want to plan or limit childbearing. These issues are the subject of the next section.

\section{Policy options for enhancing the demographic dividend: the role of family planning programs}

After 1950, population growth in Africa, Asia, and Latin America increased sharply as the spread of new medical technology and public health measures reduced death rates while birth rates remained high. Largely as a result, the world population expanded from 2.5 to 7.4 billion between 1950 and 2015 (United Nations Population Division 2019). This rapid population growth, which was sometimes unfortunately characterized as a "population explosion" in the West (Ehrlich 1968), led national and international policymakers to become concerned about the threat of this growth to improvements in the standard of living and the overall well-being of people in poor societies. Many governments in the developing world-with substantial international assistance-implemented voluntary family planning programs to provide access to and information about contraceptives (Cleland et al. 2006; Robinson and Ross 2007; May 2012). These programs aimed to assist women and men to control their reproductive lives and to avoid unwanted childbearing, thus reducing the population growth rate in the fastestgrowing regions of the world.

These family planning programs have not been without controversy since their initiation (Pritchett 1994; Connelly 2008; Mosher 2008; Bongaarts and Sinding 2009; Bongaarts and 
O'Neill 2018). The most persistent opposition has come from conservative religious and social groups, for whom one of the main concerns is that making contraception readily available encourages promiscuity and leads to a breakdown of family life. Other concerns about family planning programs have been raised by human rights and women's rights advocates who fear coercion. They point to examples of massive abuses by the Chinese government during the implementation of the one-child policy, and by the Indian government during an emergency period in the late 1970s (Sen, Germain, and Chen 1994; Connelly 2008; Mosher 2008). These abhorrent practices were and are universally condemned, and international concern over such coercive birth control practices led to the emphasis on voluntary family planning and the movement for rights-based family planning. Despite these criticisms of earlier national family planning programs and the need for ongoing vigilance to prevent coercion, most governments around the world now support and invest in family planning programs. As any form of coercion for fertility or family planning is completely unacceptable, in the text below the term "family planning program" refers strictly to voluntary programs that fully respect the rights of women and men.

Other objections to family planning programs come from economists who have argued that investments in family planning programs are not effective (e.g., Pritchett 1994). But this line of argument has been criticized for overlooking the impact of family planning programs on decreasing unwanted fertility (Lam 2011; Günther and Harttgen 2016), particularly during the rise in exposure to the risk of unwanted pregnancies that occurs as desired family size declines (Bongaarts 1994, 1997; Bongaarts and Casterline 2018). It also ignores the abundant evidence for the wide-ranging obstacles to practicing contraception noted below and the existence of large numbers of unintended pregnancies and abortions (Darroch et al. 2017).

\section{Rationale}

The choice of family planning programs as the main policy instrument to meet people's reproductive needs, and by extension to accelerate fertility decline, is based largely on the documentation of an unsatisfied demand for contraception, which is often referred to and measured as an "unmet need" for contraception (Westoff and Bankole 1995; Casterline and Sinding 2000). Unmet need refers to the status of women who are at risk of pregnancy and say they do not want to get pregnant within two years but are not currently using contraception. Many married or sexually active unmarried women report in surveys that they do not want a pregnancy within the next two years, but a substantial proportion of these women (more than half in some countries) are not using contraception. Worldwide, approximately 227 million women have an unmet need for modern contraception and are thus at risk of unplanned pregnancy (United Nations 2018).

The reasons for the nonuse of contraception among women who are motivated not to become pregnant are varied and include: a lack of access to contraceptives and related services; the cost of contraception; fear of side effects; ambivalence about a pregnancy; infrequent sexual activity; and person opposition or opposition from spouses, other family members, and religious or political leaders (Bongaarts and Bruce 1995; Casterline, Perez, and Biddlecom 1997; El-Zanaty et al. 1999; Casterline and Sinding 2000; Casterline, Sathar, and ul Haque 2001; Cleland et al. 2006). These obstacles to contraceptive use are the cause of an 
FIGURE 11: ANNUAL RATES OF REPRODUCTIVE EVENTS PER 1,000

WOMEN AGED 15-49 BY INCOME LEVEL

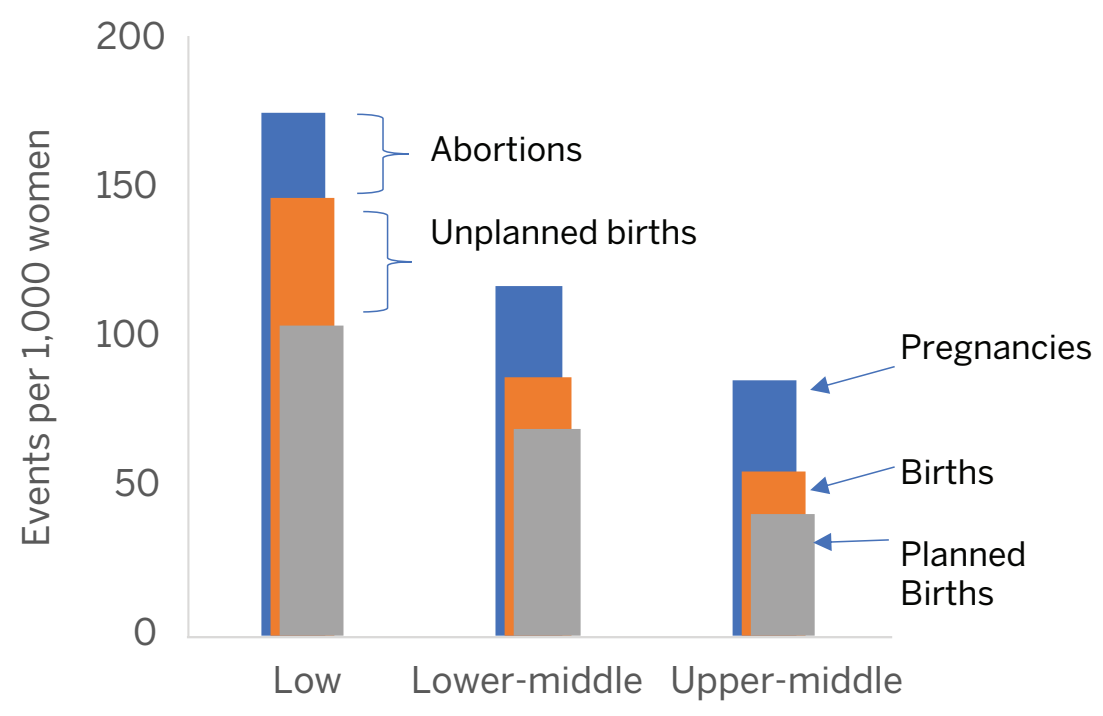

Source: Darroch et al. 2017.

unmet need for contraception. This unmet need inevitably results in unintended pregnancies, many of which can have detrimental health and economic effects for women, children, and families (Singh, Darroch, and Ashford 2014). Early in the reproductive years many unintended pregnancies and births are mistimed but ultimately wanted, while in later years unintended pregnancies or births are usually unwanted at any time because women have reached their desired family size and unplanned pregnancies mean they ultimately have more children than they want. Unintended pregnancies lead to two distinct outcomes: induced abortions and unintended births (ignoring a small number of stillbirths and miscarriages).

In low- and middle-income countries, about 76 million unintended pregnancies occur each year, accounting for 38 percent of all pregnancies across these countries. Many of these unintended pregnancies end in an induced abortion (47 million per year) and the remainder in unintended births (Darroch et al. 2017). These statistics vary by the country's level of development (see Figure 11). As expected, the overall pregnancy rate of a country is inversely related to level of development; the average rate ranges from 175 (per 1,000 women) in low-income countries to 86 in upper middle-income countries. The outcomes of these pregnancies also vary by income level. The unintended proportion ranges from 41 percent in low-income countries to 52 percent in upper middle-income countries and the proportion of unintended pregnancies ending in abortion are 39 and 70 percent, respectively.

\section{Family planning program components}

To be successful in helping women and couples avoid unintended pregnancies, family planning programs must go beyond simply providing physical access to contraceptive supplies and reduce or eliminate other obstacles to contraceptive use as well. Comprehensive 
voluntary family planning programs therefore have two broad objectives. The first is to offer women and couples easy access to a wide range of affordable, reliable, and high-quality contraceptive methods and related services. This leads to a rise in contraceptive use as women and couples are better able to implement their preferences for delaying, spacing, or limiting childbearing. The second, is to reduce or eliminate barriers men and women who want to use contraception may face. These barriers can include social norms that encourage large families or discourage contraceptive use, incorrect understanding of or rumors about contraceptive side effects, systematic bias by family planning providers, and a lack of support from men or partners, among others. Addressing these barriers to contraceptive use among those with unmet need can be done through a number of approaches, including: 1) education campaigns through mass media, called IEC (information, education, and communication) or BCC (behavioral change communication); 2) communications aimed at service providers to increase levels of knowledge and to encourage improvements in the quality of services; 3 ) increasing women's empowerment and agency; 4) collaboration with community leaders; 5) ensuring that others with significant influence on women's contraceptive behavior (e.g., husbands, partners, mothers-in-law) have accurate information about family planning and the costs and benefits of childbearing; and 6) informing the opinions and decisions of policymakers regarding laws, regulations, and other structural factors that are also barriers to contraceptive use. The reduction in obstacles and the implementation of education campaigns also play an important role in increasing overall demand for contraception and for smaller families.

By meeting these two objectives of providing access to contraceptives and addressing barriers to use, family planning programs can ensure that those who want to space or limit their births have access to high-quality contraceptive services, thus reducing unintended pregnancies.

\section{Program impact on contraceptive use}

The large numbers of unintended pregnancies occurring each year leave no doubt that millions of women and couples lack full control of their reproduction. It is therefore not surprising that well-designed family planning programs can help people implement their fertility preferences and reduce unintended births and abortions. Evaluations of these programs have found that they have a significant impact on contraceptive use and fertility (Günther and Harttgen 2016; Miller and Babiarz 2016; Bongaarts and Hardee 2019), thus demonstrating the ability of family planning programs to both meet existing contraceptive needs and encourage positive social norms and enabling environments around contraceptive

use. Three different approaches have been used to obtain impact estimates of family planning programs across a wide range of periods and contexts:

\section{Controlled experiments}

This is the gold standard for evaluating interventions, but very few large-scale controlled experiments have been conducted to assess family planning programs because they are expensive and take a long time to complete. The largest and most influential of these experiments, the Family Planning and Health Services Project (FPHSP), started in the late 1970s in Matlab, a rural district in Bangladesh (Phillips et al. 1982; Cleland, Amin, and Kamal 
1994). At that time Bangladesh was one of the poorest and most highly agricultural countries in the world, and there was widespread skepticism that family planning would be accepted in such a traditional society. The FPHSP divided the Matlab district (population of 173,000 in 1977) into experimental and control areas of approximately equal size. The control area received the same very limited services as the rest of the country, while in the experimental area comprehensive high-quality family planning services were provided, aimed at reducing the costs (monetary, social, psychological, and health) of adopting contraception. The experimental area provided free services and supplies of a range of modern contraceptive methods; home visits by well-educated female family planning workers; regular follow-up to address health concerns; comprehensive multimedia communication; menstrual regulation services; and outreach to husbands, community leaders, and religious leaders to address potential social and familial objections from men.

The impact of the program was large and immediate (Cleland et al. 1994). Within two years, contraceptive use jumped from 5 percent to 33 percent among married women in the experimental area while little change occurred in the control area. As a result, fertility declined more rapidly in the experimental than in the control area and a difference of 25 percent (around 1.5 births per woman) was maintained through the 1980 s until the services in the rest of the country were also improved.

A similar but more complex quasi-experimental study was conducted in the Navrongo district of Northern Ghana in the 1990s, where over a third of women wanted to space or limit additional births but few were using contraception. Though direct estimates of changes in contraceptive use from the Navrongo project are not available, the evaluation found the project led to improved knowledge and use of modern contraception and to a decline in the TFR of 1.0 births per woman in the initial three years of the project, a 15 percent decline in fertility relative to comparison areas (Debpuur et al. 2002).

\section{Natural experiments}

"Natural experiments" compare two populations with similar social, economic, cultural, and religious characteristics, but with differing approaches to family planning programs. Differences between the populations in contraceptive use and fertility between these populations demonstrate the potential impact of voluntary family planning (Cleland 1994; Lee et al. 1998; Bongaarts et al. 2012).

An instructive example is a comparison of Bangladesh and Pakistan, which were one country from 1947 until 1971 and have had similar cultures and levels of social and economic development. However, the countries differed remarkably in their commitment to voluntary family planning. After the success of the Matlab experiment the government of Bangladesh implemented one of the world's most comprehensive family planning programs starting around 1980, while Pakistan's program remained weak and relatively ineffective and lacked government funds and commitment (Cleland and Lush 1997).

Bangladesh's high-quality and far-reaching family planning program is likely the main cause of the large current gap in modern contraceptive prevalence rate (mCPR) among married women between the two countries. Starting at very low levels in the early 1970s the mCPR in 
FIGURE 12: PREVALENCE OF MODERN CONTRACEPTION 2015. STRONGER VS. WEAKER PROGRAM COUNTRIES

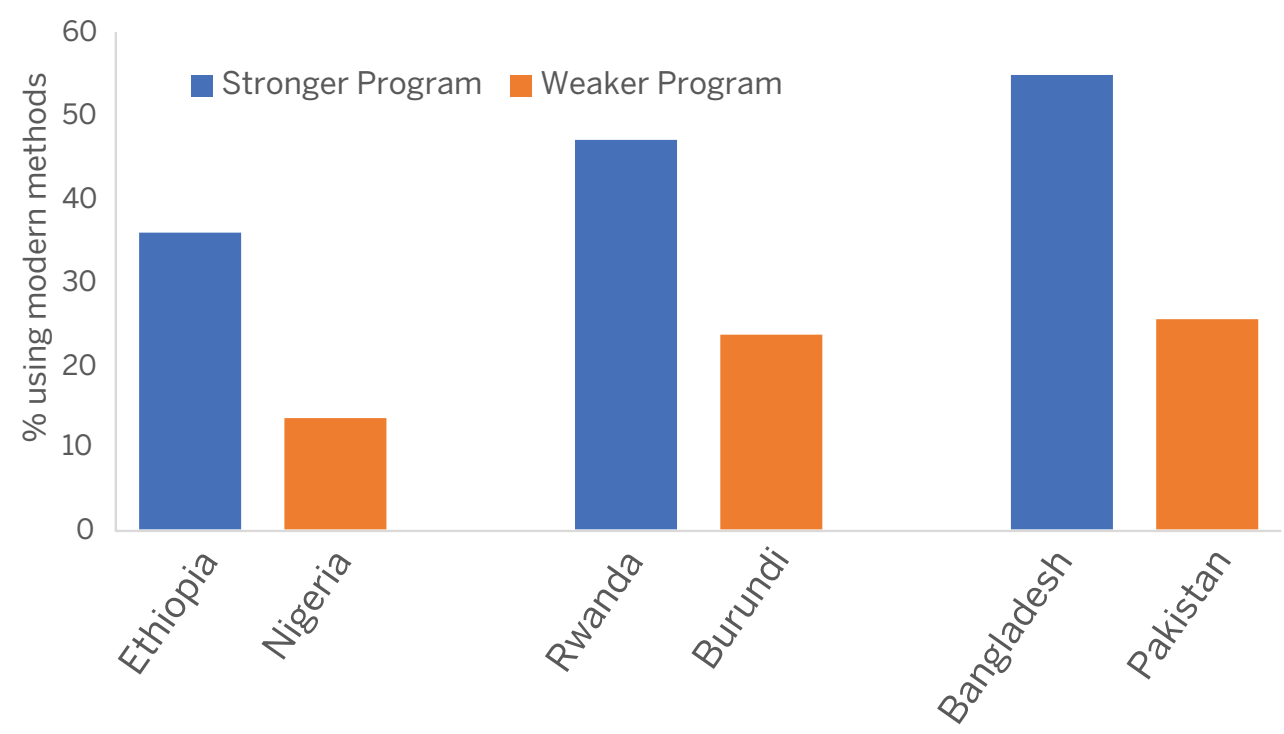

Source: United Nations Population Division 2017.

Bangladesh rose to 55.7 percent in 2015, compared to an mCPR of 28.6 percent in Pakistan, a 27.1 percentage point difference (United Nations Population Division 2017). Estimates of unmet need during the 1975-80 period are hard to come by, but showed clear differences by the early 1990s (30.5 percent in Pakistan in 1990-91 compared to 21.6 percent in Bangladesh in 1993-94), a trend that continued in the following decades (20.1 percent in Pakistan in 2012-13 compared to 13.5 percent in Bangladesh), implying that Bangladesh was better meeting the family planning needs of its population.

Similar differences in the mCPR exist for pairs of countries in SSA with comparable overall socioeconomic profiles but substantial differences in implementation of supportive family planning programs and policies: Ethiopia and Nigeria, and Rwanda and Burundi. Contraceptive use increased to substantially higher levels in countries with stronger programs (Ethiopia and Rwanda) than in corresponding weaker program countries (Nigeria and Burundi). ${ }^{3}$ The current difference between the $\mathrm{mCPR}$ of the stronger and weaker program countries ranges from 22 to 29 percent (Figure 12).

These country comparisons should be regarded as rough approximations of impact for several reasons: (1) The level of development in the pairs of countries is not exactly the same even though indicators such as the Human Development Index (HDI) are similar; (2) the difference between the weaker and stronger programs does not give an estimate of the total program impact in the strong program country, because the weaker programs have some effect that cannot be ignored; and (3) context-specific social, economic, and political factors that may directly relate to family planning programs. To address these issues of comparability, regression analyses are needed. 


\section{Regression analyses}

In the absence of experimental evidence, researchers have relied on regression analysis to estimate the fertility and contraceptive use effects of family planning programs. As noted earlier, the extensive literature on the determinants of fertility identifies two general factors as the main drivers of fertility declines in the developing world over the past half century: socioeconomic development, in particular education, and the implementation of family planning programs. Regression analyses have been used to estimate the separate impact of development vs. family programs on contraceptive use and fertility change (Pritchett 1994; Günther and Harttgen 2016; Bongaarts and Hardee 2019). In these regressions, contraceptive use or fertility are the dependent variables and the independent variables consist of a set of socioeconomic indicators, plus an indicator of family planning program effort.

A key issue in these regressions is the measurement of the strength of a program in a country, which is not straightforward. The oldest indicator is the Family Planning Program Effort (FPE) score, which has been used since the early 1970s to gauge the strength of national programs (Mauldin and Ross 1991; Ross and Smith 2011; Kuang and Brodsky 2016). To obtain this score, knowledgeable observers in each country answer questions about a variety of program characteristics and policy actions. Their responses are combined to yield an overall FPE score. Over the past three decades, the FPE score for countries has been measured in eight cycles ending in 2014. However, the FPE suffers from some shortcomings. Differences between countries and across cycles can occur simply because the experts often must make subjective assessments and the experts change over time. In addition, the questions included in the index have been refined and changed over time. As a result, differences between FPE scores of countries and trends for individual countries should be interpreted with caution.

More recently, Bongaarts and Hardee (2017) have proposed an alternative program indicator called "Public-sector family planning program impact score" to measure the quality and scope of the government's public family planning program. It equals the product of the proportion of demand that is satisfied by modern methods and the proportion of modern methods that is provided by the public sector. This score can be consistently measured over time in countries with Demographic and Health Surveys (DHS) and it does not rely on subjective assessments. It ranges from 0 in the absence of a government program to a theoretical value of 100 for the strongest public programs where all demand for contraception is met by the public sector. For simplicity we will refer to this variable as the "program score" (PS).

To provide a first look at the relationship between socioeconomic variables, program score, and contraceptive use, we plot in Figure 13 the prevalence of modern contraception (mCPR) by the mean years of schooling among women aged 20-39. The figure contains 24 markers, one for each of 24 countries in SSA, representing observations at the most recent DHS (ca. 2013). The size of the round marker is proportional to the program score of the country which ranges from 5 in DRC to 62 in Zimbabwe.

If female education were the only determinant of the $\mathrm{MCPR}$, the observations for all countries would fall on a single upward sloping line. This is clearly not the case, indicating an impact of programs and other factors. In general, the higher the level of women's educational attainment and the higher the program score, the higher the mCPR. A key finding is that at 
FIGURE 13: CONTRACEPTIVE PREVALENCE BY MEAN YEARS OF SCHOOLING AND PROGRAM SCORE (CIRCLE), 24 SUB-SAHARAN COUNTRIES 2015

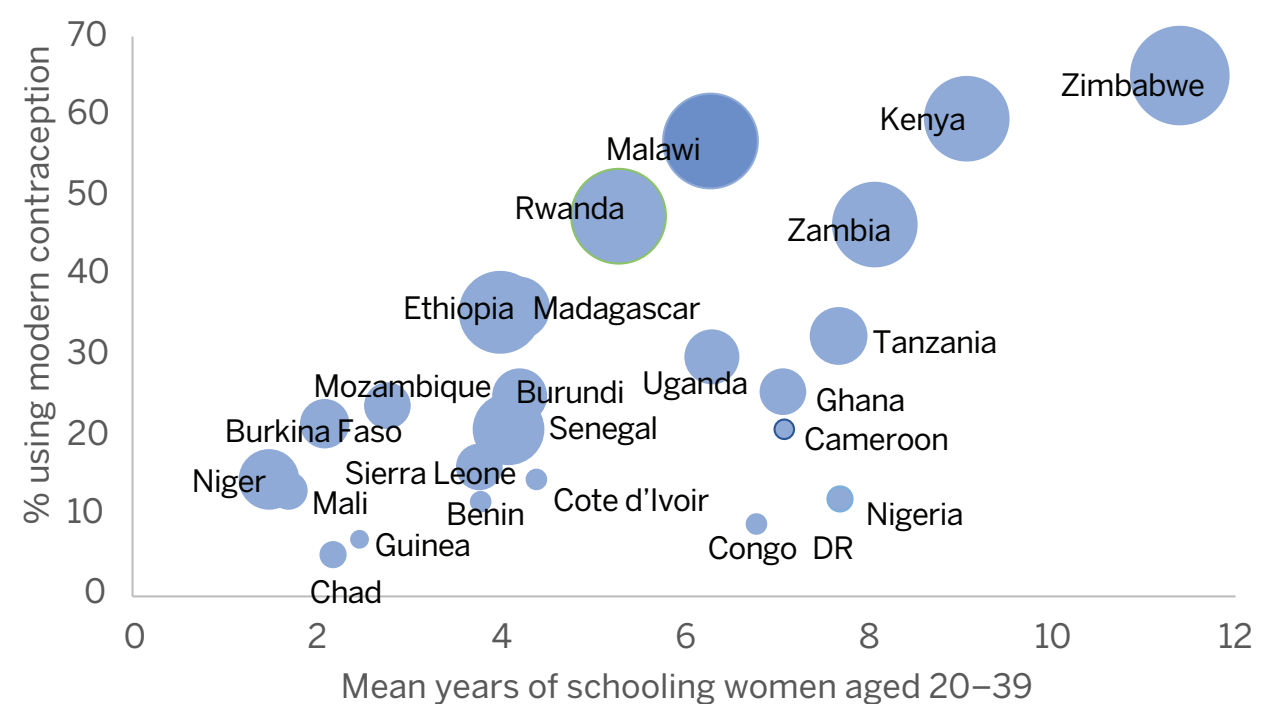

Source: United Nations Population Division 2017; Wittgenstein Center 2015.

any level of women's educational attainment, the MCPR varies widely. For example, in the countries with schooling levels between six and seven years, the mCPR ranges from 9 percent in DRC to 57 percent in Malawi. As will be shown below, the differences among these countries with similar levels of women's educational attainment are to a large extent the result of program differences. The findings in Figure 13 suggest that education and program score both have a substantial effect on $\mathrm{mCPR}$, but quantifying these effects requires formal regression analysis.

A detailed regression analysis of mCPR trends in SSA was carried out by Bongaarts and Hardee (2019). In their multivariate regressions, the mCPR was the dependent variable and the explanatory variables included: 1 ) education as measured by the average years of schooling among women aged 20-39 (“women's education”); 2) GNI/cap (PPP); 3) child mortality (ages 0-5); and 4) program score, PS. The analysis included data from 1990 to 2015 in 24 countries in SSA with at least two Demographic and Health Surveys (DHS) and with a population size above 5 million in 2015. Data from all available DHS surveys in each country were included (ICF International 2019). Fixed effects models estimated the mCPR impact of the explanatory variables. By using countries as their own controls, fixed effects models account for time-stable differences among countries, which may otherwise introduce bias into parameter estimation.

The main findings of this exercise were: 1 ) women's education and program score have a strong and highly significant effect on $\mathrm{mCPR}$, while the other explanatory variables did not; and 2) model estimates of the absolute program effect ranged from 30 percent to 40 percent in the countries with the highest program scores (i.e., Ethiopia, Kenya, Malawi, Rwanda, Zambia, and Zimbabwe). ${ }^{4}$ 
FIGURE 14: POPULATION

PROJECTIONS BANGLADESH AND

PAKISTAN

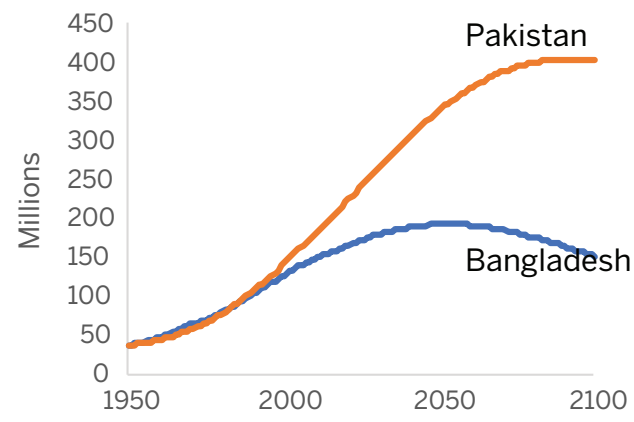

Source: United Nations Population Division 2019.
FIGURE 15: \% OF POPULATION

AGED 18-64 BANGLADESH AND PAKISTAN

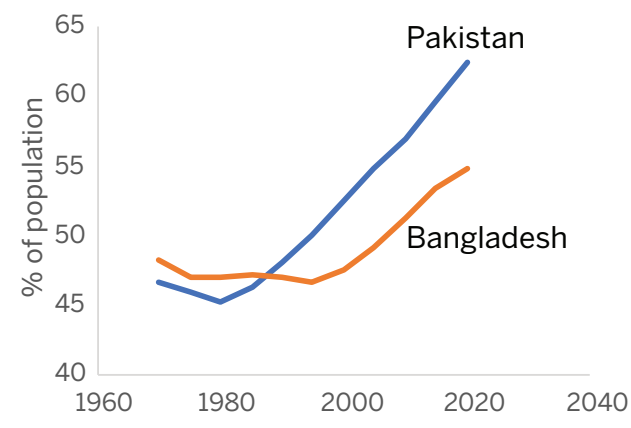

Source: United Nations Population Division 2019.

In sum, the three different approaches to estimating the mCPR impact of the best and highest-quality family planning programs yield the following results: (1) 28 percent for the controlled experiment in Matlab; (2) 22-29 percent for differences between stronger and weaker programs in "natural experiment" comparisons of countries; and (3) 30-40 percent for the absolute effects of the strongest programs in SSA in regression analyses. These findings are broadly consistent with one another because the first and second approaches underestimate the absolute program by ignoring any program effect in the weaker program countries or control area.

\section{Program impact on fertility and population trends}

By addressing the reproductive needs of couples, family planning programs reduce unmet need and raise contraceptive prevalence. This effect in turn reduces fertility and population growth, changes the age structure, and increases the demographic dividend.

To illustrate, we compare fertility and population trends in Pakistan and Bangladesh. In 197580 , the two countries had nearly the same high fertility of 6.8 births per woman, but trends diverged in subsequent decades, with more rapid declines in Bangladesh than in Pakistan. By 2010-15 Bangladesh's fertility declined to 2.2 births per woman, while in Pakistan, fertility stood at 3.8, a difference of 1.6 births per woman.

These different fertility trajectories in turn resulted in increasingly large differences in population size over time (see Figure 14). In 1980 the two populations were virtually the same size (about 80 million), but by 2100, Pakistan's population is projected to be double the size of Bangladesh's (403 vs. 151 million) (United Nations Population Division 2019). This suggests that the Bangladesh family planning program led to a large cut in the country's potential 2100 population. Fertility and population trends are also affected by levels of socioeconomic development, but this is unlikely to be the dominant explanation for the different population trajectories. Development levels as measured by the Human Development Index have been 
FIGURE 16: POPULATION

PROJECTIONS, SUB-SAHARAN

AFRICA

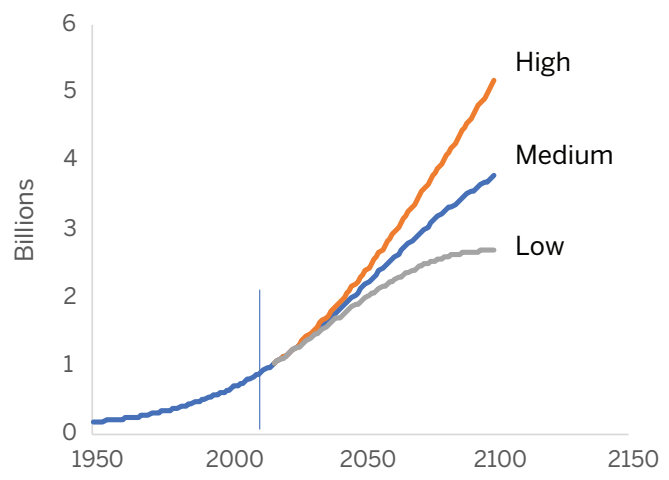

Source: United Nations Population Division 2019.
FIGURE 17: PERCENT OF

POPULATION AGED 18-64 SUB-

SAHARAN AFRICA

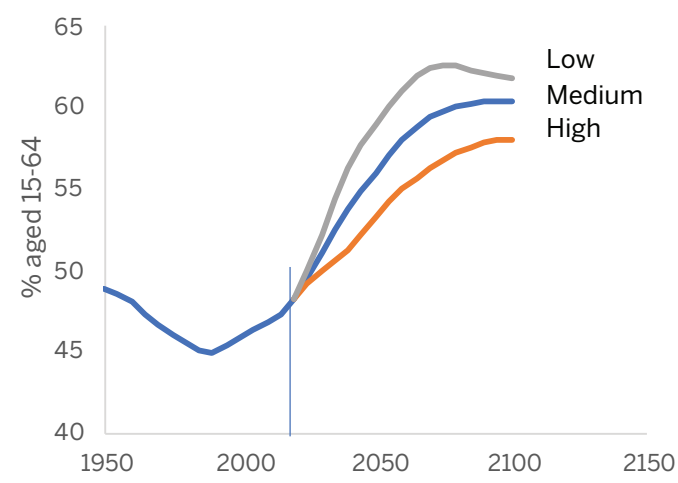

Source: United Nations Population Division 2019.

similar for Bangladesh and Pakistan, which are both poor agricultural majority-Muslim countries in South Asia (UNDP 2016).

The different fertility trajectories of Pakistan and Bangladesh also affect trends in the age structure and the demographic dividend. Figure 15 plots the proportion of working age people for the two countries from 1970 to 2015 . After 1980 (the time of the onset of fertility decline in Bangladesh), the proportion of working age grew substantially faster in Bangladesh than in Pakistan. The economy also grew faster in Bangladesh than in Pakistan after 1990 (5.9 vs. 3.9 percent per year) (World Bank 2017). There are of course other factors that contributed to the growth in Bangladesh, but the demographic tailwind is no doubt a key factor.

As noted earlier, the potential for a demographic dividend in SSA lies mostly in the future. To assess the potential demographic impact of a substantial investment in family planning programs in this continent we compare the high and low variants of the UN population projections for SSA (United Nations Population Division 2019). The only difference between these two projection variants is the fertility level assumed in the future: the high variant exceeds the low variant by one birth per woman. Such a one-birth decline is achievable with the implementation of a high-quality family planning program.

According to the medium variant, the population of SSA will quadruple in size from 1 billion in 2015 to 3.8 billion in 2100 (Figure 16). This projection assumes a steady decline in fertility and includes the impact of the AIDS epidemic. The high variant (with fertility a half birth higher than in the medium variant) projects 5.2 billion people in 2100. Despite high rates of unmet need across the region, this trajectory could well become reality if no significant further investments are made in family planning, because past fertility declines have been much slower in SSA than in Asia and Latin America. The UN's low variant projection (with fertility a half birth below the medium variant) estimates a population of 2.7 billion in 2100 . This low 
variant could well be achieved with substantial new investments in family planning to meet a rising demand for contraception as desired family size declines. In that case, the population of SSA in 2100 would be nearly 2.5 billion lower than projected in the UN's high variant and 1.1 billion below the medium variant. Clearly, a small reduction in fertility has a large impact on future population growth.

The alternative UN population projections also differ in their associated age distributions. Figure 17 plots the proportion of working age people for each projection variant in SSA. As expected, the high variant (with the highest fertility) has a much lower pace of increase in this proportion than the low variant. The peak of the dividend period occurs in the next few decades with the dividend about twice as large in the high than in the low variant (the result of a difference in the pace of increase in the proportion of the working age population).

\section{Conclusion}

The demographic dividend provides the opportunity for an additive stimulus to economic growth in developing countries with declining fertility. Policymakers interested in the potential for accelerated economic growth offered by the demographic dividend have two general options. First, invest in the underlying socioeconomic factors that are the main drivers of the transitions in fertility and desired family size. Given the evidence reviewed here, this implies strengthening education systems, especially for girls. However, education alone is not sufficient to bring about improvements in contraceptive access and use among those with demand, because women of all education levels need access to high-quality and reliable contraceptive products and services to implement their reproductive preferences. It is therefore also necessary to provide women and couples with access to and information about contraceptive methods, the main goal of family planning programs.

Education has long been a development priority for governments and international organizations. It ranks as a top priority in both the Millennium Development Goals (MDGs) and the Sustainable Development Goals (SDGs) because of its widely recognized benefits for individuals and societies, and funding for this sector has risen steadily over past decades (United Nations 2015, 2017).

The same cannot be said for family planning programs, despite strong evidence of their positive impact on health, women's empowerment, and development outcomes. Funding for family planning programs declined during the late 1990s and early 2000s, in part because of opposition from critics noted above but also because of increased attention and funding addressing HIV/AIDS and to the perception that the epidemic would halt population growth in much of SSA. Reproductive health and rights were not included in the original MDGs. Fortunately, interest in family planning programs has returned over the past decade, attributable in part to the increasingly persuasive evidence for a critical role to the demographic dividend in accelerating economic growth.

The return of family planning and reproductive health on the global agenda as one of the SDG targets (Target 3.7: "By 2030, ensure universal access to sexual and reproductive healthcare services, including for family planning, information and education, and the integration 
of reproductive health into national strategies and programmes") is a very welcome development, particularly for the millions of women around the world who lack access to these services. However, this target is part of the SDG goal number 3, which focuses on health outcomes. Unfortunately, this limited health sector positioning downplays the contribution that family planning can make as one of the most cost-effective development interventions available to governments and the international development community, leading non-health policymakers to overlook the importance of increasing access to family planning for overall population well-being. Family planning programs have wide-ranging potential benefits at the individual and societal levels, including contributing to women's empowerment, increased schooling enrollment and quality, improvements in child health (through longer birth intervals), positive impacts on economic growth, and long-term environmental sustainability (NRC 1997; Cleland et al. 2006; Kohler and Behrman 2014; Singh, Darroch, and Ashford 2014; Bongaarts 2016).

Reclassifying family planning as a development intervention, in addition to a health and human rights intervention, would give it the higher priority on the national and global development agendas it deserves. In 2014, only 1 percent of official development assistance was allocated to family planning programs. Increased investments in access to contraception for the hundreds of millions of women around the world with an unmet need for family planning would lead to a more cost-effective use of scarce development resources, thus contributing to improvements in standards of living globally.

\section{Notes}

This work was supported by a grant from the Bill \& Melinda Gates Foundation [OPP1208869].

1. This section draws heavily on the work by World Bank (2015 a, b); Ahmed and Cruz (2016); Ahmed et al. (2016); Cruz and Ahmed (2016); and Hasan et al. (2019).

2. The model was also used to examine the impact of demographic change on the global economy (World Bank 2015a), South Africa (World Bank 2015b), and the Southern African Customs Union economies (Ahmed and Cruz 2016).

3. The strength of family planning programs is measured with the PS index described below.

4. It should be emphasized that a proportion of this contraceptive use has little effect on fertility because it overlaps with postpartum infecundability (see Bongaarts 2015). 


\section{References}

Ahmed, A. and M. Cruz. 2016. "Making the Most of Demographic Change in Southern Africa." World Bank Policy Research Working Paper 7798. Washington, DC: World Bank.

Ahmed, A., M. Cruz, D. Go, M. Maliszewska, and I. Osorio-Rodarte. 2016. "How significant is sub-Saharan Africa's demographic dividend for its future growth and poverty reduction," Review of Development Economics 20(4): 762-793.

Angeles, L. 2010. "Demographic transitions: Analyzing the effects of mortality on fertility," Journal of Population Economics 23(1): 99-120.

Barro, R. 1991. “Economic growth in a cross-section of countries," Quarterly Journal of Economics 106: 407-443.

1997. Determinants of Economic Growth: A Cross-Country Empirical Study. Cambridge, MA: MIT Press.

Becker, G. 1960. "An economic analysis of fertility," in Demographic and Economic Change in Developed Countries, National Bureau of Economic Research (ed.), pp. 209-231. Princeton: Princeton University Press.

. 1965. "A theory of the allocation of time," The Economic Journal 75(299): 493-517.

_. 1981 (2nd ed. 1991). A Treatise on the Family. Cambridge, MA: Harvard University Press.

Bloom, D. and D. Canning. 2004. "Global demographic change: Dimensions and economic significance," in Global Demographic Change: Economic Impacts and Policy Challenges, Proceedings of a Symposium, Sponsored by the Federal Reserve Bank of Kansas City, pp. 9-56. Jackson Hole, WY, 26-28 August.

Bloom, D., D. Canning, G. Fink, and J. E. Finlay. 2009. “Fertility, female labor force participation, and the demographic dividend," Journal of Economic Growth 14(2): 79-101.

Bloom, D. and J. Williamson. 1998. "Demographic transition and economic miracles in emerging Asia," World Bank Economic Review 12(3): 419-456.

Bongaarts, J. 1994. "The impact of population policies: Comment [on Lant H. Pritchett]," Population and Development Review 20(3): 616-620.

. 1997. "The role of family planning programmes in contemporary fertility transitions," in The Continuing Demographic Transition, G. Jones, R. Douglas, J. Caldwell, and R. D'Souza (eds.), pp. 422444. Oxford: Clarendon Press.

. 2015. "Modeling the fertility impact of the proximate determinants: Time for a tune-up" Demographic Research 33 (19): 535-560.

_..2016. "Slow down population growth," Nature 530: 409-412.

Bongaarts, J. and J. Bruce. 1995. "The causes of unmet need for contraception and the social content of services," Studies in Family Planning 26(2): 57-75.

Bongaarts, J. and J. Casterline. 2018. "From fertility preferences to reproductive outcomes in the developing world," Population and Development Review 44(4): 793-809. 
Bongaarts, J., J. Cleland, J. Townsend, J. Bertrand, and M. Das Gupta. 2012. Family Planning Programs for the 21st Century: Rationale and Design. New York: Population Council.

Bongaarts, J. and K. Hardee. 2017. "The role of public-sector family planning programs in meeting the demand for contraception in sub-Saharan Africa," International Perspectives on Sexual and Reproductive Health 43(2): 41-50.

_. 2019. "Trends in contraceptive prevalence in sub-Saharan Africa: The roles of family planning programs and education," African Journal of Reproductive Health 23(3): 96-105.

Bongaarts, J. and B. O'Neill. 2018. "Global warming policy: Is population left out in the cold?" Science 361(6403): 650-652.

Bongaarts, J. and S. Sinding. 2009. "A response to critics of family planning programs," International Perspectives on Sexual and Reproductive Health 35(1): 39-44.

Bongaarts, J. and S. Watkins. 1996. "Social interactions and contemporary fertility transitions," Population and Development Review 22: 639-682.

Bourguignon, François and M. Bussolo. 2013. "Income distribution in computable general equilibrium modeling," in Handbook of Computable General Equilibrium Modeling, P. Dixon and D. Jorgenson (eds.), pp. 1383-1437. Amsterdam: Elsevier.

Bryant, J. 2007. "Theories of fertility decline and the evidence from development indicators," Population and Development Review 33: 101-127.

Bussolo, M., R. de Hoyos, and D. Medvedev. 2010. "Economic growth and income distribution: Linking macro economic models with household survey data at the global level," International Journal of Microsimulation 3(1): 92-102.

Caldwell, J. 1980. "Mass education as a determinant of the timing of fertility decline," Population and Development Review 6(2): 225-255.

_. 2007. Demographic Transition Theory. Dordrecht, Netherlands: Springer

Canning, D., S. Raja, and A. Yazbeck. 2015. Africa's Demographic Transition: Dividend or Disaster? Washington, DC: World Bank.

Casterline, J. 2001. "Diffusion processes and fertility transition: Introduction," in Diffusion Processes and Fertility Transition: Selected Perspectives, J. Casterline (ed.), pp. 1-77. Committee on Population, Division of Behavioral and Social Sciences and Education, National Research Council. Washington, DC: National Academy Press.

Casterline, J., A. Perez, and A. Biddlecom. 1997. “Factors underlying unmet need for family planning in the Philippines," Studies in Family Planning 28(3): 173-191.

Casterline, J., Z. Sathar, and M. ul Haque. 2001. "Obstacles to contraceptive use in Pakistan: A study in Punjab," Studies in Family Planning 32(2): 95-110.

Casterline, J. and S. Sinding. 2000. "Unmet need for family planning in developing countries and implications for population policy," Population and Development Review 26(4): 691-723.

Chesnais, J. 1990. "Demographic transition patterns and their impact on the age structure," Population and Development Review 16 (2): 327-336. 
1993. The Demographic Transition Stages, Patterns, and Economic Implications. Translated from the French by E. Kreager and P. Kreager. Oxford: Clarendon Press.

Cleland, J. 1985. “Marital fertility decline in developing countries: Theories and evidence," in Reproductive Change in Developing Countries, J. Cleland and J. Hobcraft (eds.). Oxford: Oxford University Press.

1994. “Different pathways to demographic transition," in Population: The Complex Reality: A Report of the Population Summit of the World's Scientific Academies, F. Graham-Smith (ed.). London: Royal Society; Golden, CO: North American Press.

2001a. "Potatoes and pills: An overview of innovation-diffusion contributions to explanations of fertility decline," in Diffusion Processes and Fertility Transition: Selected Perspectives, J. Casterline (ed.), pp. 39-65. Washington, DC: National Academy Press.

_. 2001b. "The effects of improved survival on fertility: A reassessment," Population and Development Review 27(Suppl.): 60-92.

. 2009. "Education and future fertility trends, with special reference to mid-transitional countries," in Completing the Fertility Transition, United Nations Population Bulletin, Special Issue Nos. 48/49: 2002.

Cleland, J., S. Bernstein, A. Ezeh, A. Faundes, A. Glasier, and J. Innis. 2006. "Family planning: The unfinished agenda," The Lancet 368(9549): 1810-1827.

Cleland, J. and L. Lush, 1997. "Population and policies in Bangladesh, Pakistan," Forum for Applied Research and Public Policy 12: 46-50.

Cleland, J., J. Phillips, S. Amin, and G. Kamal. 1994. The Determinants of Reproductive Change in Bangladesh: Success in a Challenging Environment. Washington, DC: World Bank.

Cleland, J. and C. Wilson. 1987. "Demand theories of the fertility decline: An iconoclastic view," Population Studies 41(1): 5-30.

Coale, A. 1973. "The demographic transition," Proceedings of the International Population Conference, 69. Liège: International Union for the Scientific Study of Population.

Coale, A. and E. Hoover. 1958. Population Growth and Economic Development in Low-Income Countries: A Case Study of India's Prospects. Princeton, NJ: Princeton University Press.

Coale, A. and S. Watkins (eds.). 1986. The Decline of Fertility in Europe. Princeton, NJ: Princeton University Press.

Cochrane, S. 1979. Fertility and Education: What Do We Really Know? Washington, DC: Johns Hopkins University Press.

Connelly, M. 2008. Fatal Misconception: The Struggle to Control World Population, Cambridge, MA and London: Belknap Press of Harvard University Press.

Cruz, M. and S.A. Ahmed. 2016. "On the Impact of Demographic Change on Savings, Growth, and Poverty." World Bank Policy Research Working Paper 7805. Washington, DC: World Bank.

Cutler, D., A. Deaton, and A. Lleras-Muney. 2006. "The determinants of mortality," Journal of Economic Perspectives 20(3): 97-120. 
Darroch, J. et al. 2017. Adding It Up: Investing in Contraception and Maternal and Newborn Health, 2017Supplementary Tables. New York: Guttmacher Institute. www.guttmacher.org/fact-sheet/adding-it-upcontraception-mnh-2017.

Davis, K. 1945. "The world demographic transition," The Annals of the American Academy of Political and Social Science 237: 1-11.

Debpuur, C., J. Phillips, E. Jackson, A. Nazzar, P. Ngom, and F. Binka. 2002. "The impact of the Navrongo Project on contraceptive knowledge and use, reproductive preferences, and fertility," Studies in Family Planning 33(2): 141-164.

Diamond, I., M. Newby, and S. Varle. 1999. "Female education and fertility: Examining the links," in Critical Perspectives on Schooling and Fertility in the Developing World, C. Bledsoe, J. Casterline, J. JohnsonKuhn, and J. Haaga (eds.), pp. 23-48. Committee on Population Commission on Behavioral and Social Sciences and Education, National Research Council. Washington, DC: National Academy Press.

Donaldson, P. 1990. Nature Against Us: The United States and the World Population Crisis, 1965-1980. Chapel Hill, NC: University of North Carolina Press.

Donaldson, P. and A. Ong Tsui. 1990. "The international family planning movement," Population Bulletin 45(3).

Easterlin, R. 1975. "An economic framework for fertility analysis," Studies in Family Planning 6(3): 54-63.

_. 1978. "The economics and sociology of fertility: A synthesis," in Historical Studies of Changing

Fertility, C. Tilly (ed.), pp. 57-113. Princeton, NJ: Princeton University Press.

Easterlin, R. and E. Crimmins. 1985. The Fertility Revolution: A Supply-Demand Analysis. Chicago: University of Chicago Press.

Eastwood, R. and M. Lipton. 2011. "Demographic transition in sub-Saharan Africa: How big will the economic dividend be?" Population Studies 65(1): 9-35.

Ehrlich P. 1968. The Population Bomb. San Francisco: Sierra Club Ballantine Book.

El-Zanaty, F., A. Way, S. Kishor, and J. Casterline. 1999. Egypt In-depth Study on the Reasons for Non-use of Family Planning. Cairo: National Population Council.

Gaylor, O. 2005. "The demographic transition and the emergence of sustained economic growth," Journal of the European Economic Association 3(2-3): 494-504.

Günther I. and K. Harttgen. 2016. "Desired fertility and number of children born across time and space," Demography 53(1): 55-83.

Hadden, K. and B. London. 1996. "Educating girls in the third world," International Journal of Comparative Sociology 37(1-2): 31-46.

Harkavy, O. 1995. Curbing Population Growth: An Insider's Perspective on the Population Movement. New York: Plenum Press.

Hasan, R., H. Moucheraud, S. Samaha, S. Troiano, A. Ahmed, I. Osorio-Rodarte, E. Suzuki, M. Sexton, E. Pradhan, S. Madhavan, and C. Bou-Habib. 2019. Demographic Dividend in DRC: Catalyzing Economic Growth through Demographic Opportunities. Washington, DC: World Bank (mimeo). 
Hauser, P. and O. Duncan. 1959. The Study of Population. An Inventory and Appraisal. Chicago: University of Chicago Press.

Headey, D. and A. Hodge. 2009. "The effect of population growth on economic growth: A metaregression analysis of the macroeconomic literature," Population and Development Review 35(2): 221-248.

Higgins, M. and J. Williamson. 1997. "Age structure dynamics in Asia and dependence on foreign capital," Population and Development Review 23(2): 261-293.

Hornik, R. and E. McAnany. 2001. "Mass media and fertility change," in Diffusion Processes and Fertility Transition: Selected Perspectives, John Casterline (ed.), pp. 208-239. Washington, DC: National Academy Press.

Human Mortality Database. 2019. University of California, Berkeley, and Max Planck Institute for Demographic Research. Available at www.mortality.org or www.humanmortality.de.

ICF International. 2019. The DHS Program STATcompiler. Available at: https://www.statcompiler.com.

Jejeebhoy, S. 1995. Women's Education, Autonomy, and Reproductive Behaviour: Experience from Developing Countries. Oxford: Clarendon Press.

Kara, M., D. Canning, and J. Wilde. 2017. "The effect of fertility decline on economic growth in Africa: A macrosimulation model," Population and Development Review 43(S1): 237-263.

Kelley, A. 2001.“"The population debate in historical perspective: Revisionism revised," in Population Matters, N. Birdsall, A. Kelley, and S. Sinding (eds.), pp. 24-54. New York: Oxford University Press.

Kelley, A. and R. Schmidt. 1995. "Aggregate population and economic growth correlations: The role of the components of demographic change," Demography 32(4): 543-555.

_.2001. "Economic and demographic change: A synthesis of models, findings, and perspectives," in Population Matters, N. Birdsall, A. Kelley, and S. Sinding (eds.), pp. 67-105. New York: Oxford University Press.

_. 2005. "Evolution of recent economic-demographic modeling: A synthesis," Journal of Population Economics 18(2): 275-300.

_. 2007. "A century of demographic change and economic growth: The Asian experience in regional and temporal perspective," in Population Change, Labor Markets and Sustainable Growth: Towards a New Economic Paradigm, A. Mason and M. Yamaguchi (eds.), pp. 39-74. Amsterdam: Elsevier.

Kinugasa, T. and A. Mason. 2007. “Why countries become wealthy: The effects of adult longevity on saving," World Development 35(1): 1-23.

Kirk, D. 1996. “Demographic transition theory," Population Studies 50(3): 361-387.

Knodel, J. and E. van de Walle. 1979. "Lessons from the past: Policy implications of historical fertility studies," Population and Development Review 5(2): 217-245.

Kohler, H. 2001. Fertility and Social Interactions: An Economic Perspective. Oxford: Oxford University Press.

Kohler, H.P. and J. Behrman. 2014. Benefits and Costs of the Population and Demography Targets for the Post-2015 Development Agenda Post-2015 Consensus. Working Paper October 2014. Copenhagen: The 
Copenhagen Consensus Center. Available at: https://www.copenhagenconsensus.com/sites/default/ files/population_assessment_-_kohler_behrman.pdf.

Kravdal, O. 2002. "Education and fertility in sub-Saharan Africa: Individual and community effects," Demography 39(2): 233-250.

Kuang, B. and I. Brodsky. 2016. “Global trends in family planning programs, 1999-2014," International Perspectives on Sexual and Reproductive Health 42(1): 33-44.

Kuznets, S. 1967. “Population and economic growth," Proceedings of the American Philosophical Society 111(3), 170-193.

Lam, D. 2011. "How the world survived the population bomb: Lessons from 50 years of extraordinary demographic history," Demography 48(4): 1231-1262.

Landry, A. 1934. La Révolution Démographique. Paris: Sirey.

Lee, R. and R. Bulatao. 1983. "The demand for children: A critical essay," in Determinants of Fertility in Developing Countries: A Summary of Knowledge, R. Bulatao and R. Lee (eds.). New York: Academic Press.

Lee, K., L. Lush, G. Walt, and J. Cleland. 1998. "Family planning policies and programmes in eight lowincome countries: A comparative policy analysis," Social Science in Medicine 47(7): 949-959.

Lee, R. and A. Mason. 2006. "What is the demographic dividend?" Finance and Development 43(3): 16.

Livi-Bachi, A. 1992. Concise History of World Population. London: Blackwell Publishers.

Lloyd, C. 2003. “Education," in Encyclopedia of Population, P. Demeny and G. McNicoll (eds.), pp. 278-283. New York: Macmillan.

Lutz, W. and V. Skirbekk. 2014. "How education drives demography and knowledge informs projections," in World Population and Human Capital in the Twenty-First Century, W. Lutz, W. Butz, and K. Samir (eds.). Oxford: Oxford University Press.

Mason, A. and T. Kinugasa. 2008. "East Asian economic development: Two demographic dividends," Journal of Asian Economics 19(5): 389-399.

Mauldin, W. and J. Ross. 1991. "Family planning programs: Efforts and results, 1982-89," Studies in Family Planning 22(6): 350-367.

May, J. 2012. World Population Policies: Their Origin, Evolution, and Impact. New York: Springer.

Meadows, D., D. Meadows, J. Randers, and W. Behrens III. 1972. The Limits to Growth. New York: Universe Books.

Miller, G. and K. Singer Babiarz. 2016. "Family planning program effects: Evidence from microdata," Population and Development Review 42(1): 7-26.

Montgomery, M. and J. Casterline. 1993. "The diffusion of fertility control in Taiwan: Evidence from pooled cross-section time-series models," Population Studies 47: 457-479.

_. 1996. "Social learning, social influence, and new models of fertility," Population and Development Review 22(Suppl.): 151-175.

Mosher, S. 2008. Population Control-Real Costs, Illusory Benefits. Edison, NJ: Transaction Publishers. 
Murtin, F. 2013. "Long-term determinants of the demographic transition, 1870-2000," The Review of Economics and Statistics 95(2): 617-631.

National Academy of Sciences (NAS). 1971. Rapid Population Growth: Consequences and Policy Implications. Baltimore: Johns Hopkins Press for the National Academies of Sciences.

1986. Population Growth and Economic Development. Washington, DC: National Academy of Sciences.

National Research Council (NRC). 1997. Reproductive Health in Developing Countries: Expanding Dimensions, Building Solutions. Washington, DC: The National Academies Press. https://doi. org/10.17226/5500.

Notestein, F. 1945, “Population: The long view," in Food for the World, T. Schultz (ed.), pp. 36-57. Chicago: University of Chicago Press.

Phillips, J., W. Stinson, S. Bhatia, M. Rahman, and J. Chakraborty. 1982. "The demographic impact of the Family Planning-Health Services Project in Matlab, Bangladesh," Studies in Family Planning 13(5): 131-140.

Pritchett, L. 1994. "Desired fertility and the impact of population policies," Population and Development Review 20(1): 1-55.

Retherford, R. and J. Palmore. 1983. "Diffusion processes affecting fertility regulation," in Determinants of Fertility in Developing Countries, R. Bulatao and R. Lee (eds.), Volume 2. New York: Academic Press.

Riley, J. 2001. Rising Life Expectancy: A Global History. Cambridge: Cambridge University Press.

Robinson, W. and J. Ross. 2007. "Family planning: The quiet revolution," in The Global Family Planning Revolution: Three Decades of Population Policies and Programs, W. Robinson and J. Ross (eds.), pp. 421-449. Washington, DC: World Bank.

Rochat, R., D. Kramer, P. Seanayake, and C. Howell. 1980. "Induced abortion and health problems in developing countries," The Lancet 2(8192): 484.

Rogers, E. 1973. Communication Strategies for Family Planning. New York: Free Press.

_. 2003. Diffusion of Innovations. New York: Free Press.

Ross, J. and E. Smith. 2011. “Trends in national family planning programs, 1999, 2004 and 2009," International Perspectives on Sexual and Reproductive Health 37(3): 125-133.

Schultz, P. 1976. "Determinants of fertility: A microeconomic model of choice," in Economic Factors in Population Growth, A. Coale (ed.), pp. 89-120. New York: Halstead Press.

1994. "Human capital, family planning and their effects on population growth," American Economic Review 84(2): 255-260.

_. 2002. "Fertility transition: Economic explanations," in Pergamon International Encyclopedia of the Social and Behavioral Sciences, N. Smelser and P. Baltes (eds), pp. 5578-5584. Oxford: Oxford University Press.

Sen, G., A. Germain, and L. Chen. 1994. Population Policies Reconsidered: Health, Empowerment and Rights. Boston: Harvard University Press. 
Simon, J. 1981. The Ultimate Resource. Princeton, NJ: Princeton University Press.

Sinding, S. 2007. "Overview and perspective," in The Global Family Planning Revolution: Three Decades of Population Policies and Programs, W. Robinson and J. Ross (eds.), pp. 1-12. Washington, DC: The World Bank.

Singh, S., J. Darroch, and L. Ashford. 2014. Adding It Up: The Costs and Benefits of Investing in Sexual and Reproductive Health. New York: Guttmacher Institute.

Summers, L. 1992a. "Investing in all the people." The Pakistan Development Review 31(4): 367-404.

_.1992b. “The most influential investment," Scientific American (August): 132.

Thompson, W. 1929. “Population," American Journal of Sociology 34(6): 959-975.

Tietze, C. 1981. Induced Abortion: A World Review. New York: Population Council.

United Nations. 1954. "Framework for future population estimates, 1950-1980, by world regions," in Proceedings of the World Population Conference, pp. 283-328. New York: United Nations.

_. 1958. "The future growth of world population," Population Studies 28, ST/SON Series N28. New York: United Nations.

_. 2015. The Millennium Development Goals Report 2015. New York: United Nations.

_. 2017. The Sustainable Development Goals Report. New York: United Nations.

United Nations Development Program (UNDP). 2016. Human Development Report 2016: Human

Development for Everyone. New York: UNDP.

United Nations Population Division. 1999. The World at Six Billion, Working Paper No. ESA/P/WP.154. New York: United Nations.

_. 2015. World Population Prospects: The 2015 Revision. New York: United Nations.

_. 2017. World Contraceptive Use 2017. New York: United Nations.

_. 2018. Estimates and Projections of Family Planning Indicators 2018. New York: United Nations.

_. 2019. World Population Prospects: The 2019 Revision. New York: United Nations.

Watkins, S. 1986. "Conclusions," in The Decline of Fertility in Europe, A. Coale and S. Watkins (eds.), pp. 420-449. Princeton, NJ: Princeton University Press.

1987. "The fertility transition: Europe and the third world compared," Sociological Forum 2(4):

645-673.

Westoff, C. and A. Bankole. 1995. “Unmet need: 1990-1994," Demographic and Health Surveys Comparative Studies 16. Calverton, MD: Macro International.

Willis, R. 1974. "Economic theory of fertility behavior," in Economics of the Family: Marriage, Children and Human Capital, T. Schultz (ed.), pp. 25-75. Chicago: University of Chicago Press.

Wittgenstein Centre for Demography and Global Human Capital. 2015. Wittgenstein Centre Data Explorer Version 1.2. Available at: http://www.wittgensteincentre.org/dataexplorer. 
Wolpin, K. 1998. "The impact of infant and child mortality risk on fertility," in From Death to Birth: Mortality Decline and Reproductive Change, M. Montgomery and B. Cohen (eds.), pp. 74-111. Washington, DC: The National Academies Press.

World Bank. 2015a. Global Monitoring Report 2015/2016: Development Goals in an Era of Demographic Change. Washington, DC: World Bank Group.

2015b. South Africa Economic Update: Jobs and South Africa's Changing Demographics. Washington, DC: World Bank Group.

_.2017. World Development Indicators. Washington, DC: World Bank. Available at: https://data. worldbank.org/indicator. 